\title{
Solid Electrolyte Interphase Growth and Capacity Loss in Silicon Electrodes
}

\author{
Alison L. Michan,$^{\dagger}$ Giorgio Divitini, ${ }^{\ddagger}$ Andrew J. Pell, ${ }^{\dagger}$ Michal Leskes, ${ }^{\dagger}$ Caterina \\ Ducati, ${ }^{\ddagger}$ and Clare P. Grey ${ }^{* \dagger}$
}

Department of Chemistry, University of Cambridge, Lensfield Road, Cambridge, CB2

$1 E W$, United Kingdom, and Department of Material Science and Metallurgy, University of

Cambridge, 27 Charles Babbage Road, Cambridge CB3 OFS, United Kingdom

E-mail: cpg27@cam.ac.uk

\begin{abstract}
The solid electrolyte interphase (SEI) of the high capacity anode material Si is monitored over multiple electrochemical cycles by ${ }^{7} \mathrm{Li},{ }^{19} \mathrm{~F}$, and ${ }^{13} \mathrm{C}$ solid-state nuclear magnetic resonance spectroscopies, with the organics dominating the SEI. Homonuclear correlation experiments are used to identify the organic fragments $-\mathrm{OCH}_{2} \mathrm{CH}_{2} \mathrm{O}-,-\mathrm{OCH}_{2} \mathrm{CH}_{2}-,-\mathrm{OCH}_{2} \mathrm{CH}_{3}$, and $-\mathrm{CH}_{2} \mathrm{CH}_{3}$ contained in both oligomeric species and lithium semicarbonates $\mathrm{ROCO}_{2} \mathrm{Li}, \mathrm{RCO}_{2} \mathrm{Li}$. The SEI growth is correlated with increasing electrode tortuosity by using focused-ion beam and scanning electron microscopy. A 2-stage model for lithiation capacity loss is developed: initially, the lithiation capacity steadily decreases, $\mathrm{Li}^{+}$ is irreversibly consumed at a steady rate, and pronounced SEI growth is seen. Later, below $50 \%$ of the initial lithiation capacity, less $\mathrm{Si}$ is (de)lithiated resulting in less volume expansion and contraction; the rate of $\mathrm{Li}^{+}$being irreversibly consumed declines, and the Si SEI thickness stabilizes. The decreasing lithiation capacity is primarily attributed to kinetics, the increased electrode tortuousity severely limiting $\mathrm{Li}^{+}$ion diffusion through the bulk of the electrode. The resulting changes in the lithiation processes seen in the electrochemical capacity curves are ascribed to non-uniform lithiation, the reaction commencing near the separator/on the surface of the particles.
\end{abstract}

\section{Introduction}

In order for new electrode materials to be practically implemented in a Li-ion battery, sufficient capacity retention over many electrochemical cycles must be achieved. Since most negative electrode materials operate outside the electrochemical window of the electrolyte, this requires the formation of a stable solid electrolyte interphase (SEI) on the surfaces of the electrode so as to limit electrolyte breakdown. ${ }^{1-7}$ In this study, we examine the electrode material Si, which forms an alloy with Li during electrochemical cycling. With its fully lithiated state of $\mathrm{Li}_{15} \mathrm{Si}_{4}$ corresponding to an excellent theoretical capacity of $3579 \mathrm{mAhg}^{-1}$, this material has the potential to improve the performance of Li-ion batteries. ${ }^{8-10}$ However, to accommodate $15 \mathrm{Li}$ per 4 Si atoms, a considerable volume expansion of up to $300 \%$ occurs during electrochemical cycling. ${ }^{9,11,12}$ In contrast, the commonly-used electrode material graphite, with a theoretical capacity of $372 \mathrm{mAhg}^{-1}$, has a much lower volume expansion of $10 \% .{ }^{9}$ The extreme volume expansion in $\mathrm{Si}$ systems, and other electrode materials forming $\mathrm{Li}$ alloys in Li-ion batteries, is thought to underlie their poor capacity retention; the volume expansion leads to mechanical failure and uncontrolled electrolyte decomposition preventing the formation of a stable SEI. ${ }^{13,14}$

With a fundamental understanding of the failure mechanisms in Si Li-ion battery systems, it may be possible to develop a successful strategy to achieve longterm capacity retention. Toward this goal, some strategies have already been explored. For example, the negative consequences of volume expansion may be mitigated using capacity-limited cycling by preventing the formation of the $\mathrm{Li}_{15} \mathrm{Si}_{4}$ phase. ${ }^{15}$ The use of alternative Si morphologies may also be a way forward. For example, improved capacity retention has been achieved using $\mathrm{Si}$ nanowires, in part because these studies are performed at high rates, SEI formation depending strongly on the time the electrode spends at low voltages; electrical wiring of the nanowires to the current collector for the Si nanowires grown via chemical vapor deposition also aids retention. ${ }^{16,17}$ Alternatively, the Si particle size can be reduced to nano particles; however, reducing the particle size leads to a greater surface area for electrolyte decomposition. Electrolyte additives are another strategy: Si systems cycled with electrolytes containing additives such as vinylene carbonate (VC) 
and fluoroethylene carbonate (FEC) show noticeably improved capacity retention. ${ }^{18-20}$ These additive studies provide the motivation for a deeper understanding of the chemical composition and structure of what makes an optimal SEI. Toward this goal, we monitor the chemical composition and growth of the SEI formed in a Si composite electrode system with a standard electrolyte $\left(1 \mathrm{M} \mathrm{LiPF}_{6}\right.$ in ethylene carbonate (EC) / dimethyl carbonate (DMC)). A fundamental understanding of the failure mechanisms in this system will aid optimization of electrochemical cycling, electrode formulation, and the use of electrolyte additives.

Innovative experimental strategies can provide new insight, with the study of the SEI being impeded by the experimental challenges of probing the air sensitive, ${ }^{21,22}$ amorphous, nanoscale-thick interface, which grows in situ during electrochemical cycling. In our previous study we employed solid-state NMR (ssNMR) using ${ }^{13} \mathrm{C}$-labelled electrolyte solvents to probe the SEI formed in the first electrochemical cycle of $\mathrm{C} / \mathrm{Si}$ binderfree composite electrodes. ${ }^{23}$ In this study, we extend the ssNMR approach to multi-cycled electrodes, containing $50 \mathrm{~nm}$ average particle size Si mixed with conductive C and a carboxymethylcellulose (CMC) binder, in order to monitor the growth of both the organic and inorganic components of the SEI. The local environments in the SEI are probed by ssNMR, ssNMR being a particularly advantageous technique in characterizing disordered systems, in contrast to other techniques such as $\mathrm{X}$-ray diffraction (XRD). Furthermore, ssNMR is used to probe the bulk of the thick (up to approximately $100 \mathrm{~nm}$ ) SEI layer in contrast to characterization techniques which are limited to the outermost layer of the SEI, such as X-ray photoelectron spectroscopy (XPS). Using ssNMR we can unambiguously detect chemicallybonded environments relevant to the organic molecules and oligomers of the SEI. Additionally we examine the electrochemistry of the system and perform analysis of the electrode samples using Focused-ion Beam (FIB) and Scanning Electron Microscopy (SEM) characterization to observe the $\mathrm{Si}$ electrode pore structure and mechanical failure. The microstructure characterization complements the chemical analysis obtained by ssNMR and shows the relationship between SEI growth, electrode pore structure, and electrochemical capacity loss. Finally, we use electrochemistry to separately characterize the SEI formed on the conductive $\mathrm{C}$ in the system, demonstrating how capacity (loss) in the composite system may be influenced by the amount of conductive $\mathrm{C}$ in the formulation.

\section{Experimental Methods}

${ }^{13}$ C-enriched Electrolyte Preparation. Enriched electrolytes were prepared in an $\mathrm{Ar}$ glovebox (typically $\mathrm{H}_{2} \mathrm{O}$ and $\mathrm{O}_{2}<0.1$ ppm) by dissolving $1 \mathrm{M}$ lithium hexafluorophosphate $\mathrm{LiPF}_{6}$ (Sigma Aldrich, battery grade, $\geq 99.99 \%$ ) in ethylene carbonate (EC) (Sigma Aldrich, 97\%, ${ }^{13}$ C-labelled 99 atom \%, and Sigma Aldrich battery grade anhydrous, $\geq 99 \%$, non-labelled, $\leq 0.005 \%$ $\mathrm{H}_{2} \mathrm{O}$ ) and dimethyl carbonate (DMC) (Sigma Aldrich, $\overline{97} \%,{ }^{13} \mathrm{C}-$ labelled 99 atom \% and Sigma Aldrich, battery grade anhydrous, $\geq 99 \%$, non-labelled, $\leq 0.002 \% \mathrm{H}_{2}$ O) $1: 1 \mathrm{w} / \mathrm{w}$. Both ${ }^{13}$ C-labelled EC and non-labelled battery grade EC were dried under vacuum in a mini-desiccator to remove any trace water, and transferred to an $\mathrm{Ar}$ glovebox. Both the ${ }^{13} \mathrm{C}$-labelled DMC and battery grade DMC were dried using $4 \AA$ molecular sieves to remove any moisture and transferred to an Ar glovebox. The dry DMC $(<10 \mathrm{ppm}$ $\mathrm{H}_{2} \mathrm{O}$, by Metrohm 899 Karl Fischer Coulometer) was mixed with the dry non-labelled battery grade EC and used to dilute the dried $99 \%$ enriched carbonates. $25 \%{ }^{13} \mathrm{C}$ enriched electrolytes were prepared with either fully-labelled ${ }^{13} \mathrm{C} \mathrm{EC}$ or fully-labelled ${ }^{13} \mathrm{C} \mathrm{DMC}$ (Figure 1). Battery grade LP30 $\left(1 \mathrm{M} \mathrm{LiPF}_{6}\right.$ in EC/DMC 1:1 v/v by Aldrich, $\leq 15 \mathrm{ppm} \mathrm{H}_{2} \mathrm{O}$ ) was used when no isotope enrichment was required.

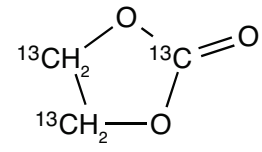

(a)

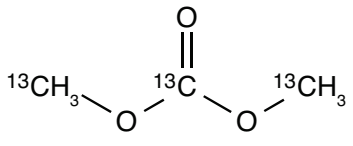

(b)
Figure 1: ${ }^{13} \mathrm{C}$-enriched (a) EC and (b) DMC electrolyte molecules.

Electrode Formulation and Electrochemical Cycling. Crystalline Si powder (Sigma Aldrich, average particle size 50 $\mathrm{nm},<100 \mathrm{~nm}, \geq 98 \%, 325$ mesh) was mixed with Carbon SuperP (Timcal) and sodium carboxymethylcellulose (CMC) (Sigma Aldrich, average $700,000 \mathrm{gmol}^{-1}, 0.80-0.95$ degree of substitution) in equal mass ratios (1:1:1) of $200 \mathrm{mg}$. A slurry was obtained by mixing the powders with $6 \mathrm{~mL}$ distilled water in a $70 \mathrm{~mL}$ stainless steel ball mill container using two $1 / 2$ in. diameter balls for 30 minutes using a high energy Spex SamplePrep 8000M Mixer/Mill. The slurry was cast onto a copper substrate and dried at room temperature. $1 / 2$ in. diameter electrodes were punched out of the dried film. These electrode samples were characterized using SEM and scanning transmission electron spectroscopy (S/TEM), seen in the Supporting Information, Figure S1; the Si particle oxidation layer is approximately 8-15 $\mathrm{nm}$.

The electrodes were each dried for 2 hours at $100{ }^{\circ} \mathrm{C}$ in a vacuum oven and then under dynamic vacuum in the pre-chamber of an Ar glovebox overnight before assembly into 2032 coin cells in an Ar glovebox (typically $\mathrm{O}_{2}$ and $\mathrm{H}_{2} \mathrm{O}<0.1 \mathrm{ppm}$ ). The coin cell parts were dried with a minimum standard of $60^{\circ} \mathrm{C}$ for a week followed by vacuum pumping in the pre-chamber of the Ar glovebox. The weight of the active material was approximately 0.5 mg per electrode, with each electrode individually weighed inside the glovebox prior to assembly. A counter electrode of Li metal (Sigma Aldrich, Li metal ribbon, $0.38 \mathrm{~mm}$ thickness, 99.9\%) was used. The Li metal counter electrode surfaces were cleaned using a soft brush before cell assembly. Standard porous glass fibre mat separators (Whatman GF/B) were saturated with electrolyte. An additional Celgard 2340 separator layer was used against the electrode surface to avoid any glass fibre sticking to the surface of the electrode samples.

The coin cells were galvanostatically cycled (using a Biologic VSP or MPG-2). The constant current discharge rate over 30 hours, $\left(C / X, X=30\right.$ hours) was calculated by: $I=C_{\mathrm{Si}} m_{\mathrm{Si}} X^{-1}$, with $m_{\mathrm{Si}}$ being the mass of $\mathrm{Si}$ and $C_{\mathrm{Si}}$ being $3579 \mathrm{mAhg}^{-1}$ corresponding to the theoretical capacity of crystalline $\mathrm{Li}_{15} \mathrm{Si}_{4}$. The coin cells, prepared with enriched electrolytes, were cycled for 1 , 30 , and 60 cycles using voltage limits of $1 \mathrm{mV}$ and $2 \mathrm{~V}$. At the end of cycling, the coin cells were held at $2 \mathrm{~V}$ for 12 hours. After cycling, the coin cells were disassembled under Ar and dried under dynamic vacuum in the pre-chamber of the glovebox. No solvent was used to rinse excess electrolyte from the samples to avoid any structural or compositional change to SEI grown on the electrode surfaces. The electrochemical data were processed using the Biologic EC-Lab V10.34 and Gnuplot V4.6 software.

Carbon SuperP powder electrodes, without $\mathrm{Si}$ and $\mathrm{CMC}$ binder, were assembled into coin cells using the same method as described for the $\mathrm{Si}$ composite electrodes. The conductive $\mathrm{C}$ was dried on a vacuum line at $100^{\circ} \mathrm{C}$ for 2 days before being used in the 2032 coin cells in $1.5 \mathrm{mg}$ quantities.

Solid State NMR. Ex-situ multinuclear ssNMR spectra were obtained on 11.7 T Bruker Avance III $500 \mathrm{MHz}$ and 9.4 T Bruker 
Avance $400 \mathrm{MHz}$ spectrometers. Samples were packed under Ar, avoiding any exposure to ambient air, into rotors of $2.5 \mathrm{~mm}$ outer diameter. Magic-angle spinning (MAS) frequencies ranged from 10 to $30 \mathrm{kHz}$, spinning under $\mathrm{N}_{2} \cdot 2-4$ electrode samples (of $\sim 1.5$ $\mathrm{mg}$ ) were combined to fill the rotors and enhance signal in the experiments. ${ }^{1} \mathrm{H}$ and ${ }^{13} \mathrm{C}$ chemical shifts were externally referenced to adamantane $\left({ }^{1} \mathrm{H} 1.9 \mathrm{ppm},{ }^{13} \mathrm{C} 38.5 \mathrm{ppm}, \mathrm{CH}_{2}\right)$, and ${ }^{7} \mathrm{Li}$ and ${ }^{19} \mathrm{~F}$ to $\mathrm{LiF}\left({ }^{7} \mathrm{Li}-1 \mathrm{ppm},{ }^{19} \mathrm{~F}-204 \mathrm{ppm}\right) .{ }^{24,25}$ The data were processed using the Bruker TOPSPIN software and analyzed using the dmfit software. ${ }^{26}$ Typical radio frequency (RF) field strengths used were $\left({ }^{1} \mathrm{H}\right) 135 \mathrm{kHz},\left({ }^{7} \mathrm{Li}\right) 185 \mathrm{kHz},\left({ }^{19} \mathrm{~F}\right) 115 \mathrm{kHz}$, and $\left({ }^{13} \mathrm{C}\right)$ $125 \mathrm{kHz}$.

Samples prepared with each of the ${ }^{13} \mathrm{C}$-labelled electrolyte solvents (Figure 1-a, b) were investigated by direct excitation ${ }^{13} \mathrm{C},{ }^{7} \mathrm{Li}$, and ${ }^{19} \mathrm{~F}$ ssNMR experiments to obtain quantitative information on the chemical environments. The ${ }^{13} \mathrm{C}$ spectra were acquired using swept-frequency two-pulse phase modulation (swfTPPM) ${ }^{27}{ }^{1} \mathrm{H}$ decoupling at $90-100 \mathrm{kHz}$. Two-dimensional (2D) cross polarization $(\mathrm{CP}){ }^{13} \mathrm{C}$ homonuclear experiments were performed, using a refocused INADEQUATE (Incredible Natural Abundance DoublE QUAntum Transfer Experiment) pulse sequence, to detect directly bonded $\mathrm{C}$ functional groups. ${ }^{28-31}{ }^{1} \mathrm{H}$ ${ }^{13} \mathrm{C} \mathrm{CP}$ experiments were used to detect local environments with these nuclei in close spatial proximity by transferring magnetization from ${ }^{1} \mathrm{H}$ to ${ }^{13} \mathrm{C}$ nuclei. Dipolar dephasing (interrupted decoupling ${ }^{1} \mathrm{H}-{ }^{13} \mathrm{C}$ cross polarization experiments allowed differentiation between protonated and non-protonated environments. ${ }^{25,32}$

Further experimental details are given in the Supporting Information.

SEM, FIB, and TEM. Electrode samples were transported from the Ar glovebox to the FIB and SEM instrument in sealed transport bags and transferred into the loading chambers with minimal ambient exposure ( $<5 \mathrm{~min})$. Cross-sectional FIB/SEM was carried out in a FEI Helios Nanolab. A protective platinum layer was deposited onto the electrode surfaces prior to the FIB cuts to preserve surface structure. Milling was performed at 30 $\mathrm{kV}$, with currents of $\sim 1 \mathrm{nA}$ and $\sim 100 \mathrm{pA}$ for rough cut and polishing steps respectively. Due to the FIB/SEM geometry, SEM images were acquired at an angle of $38^{\circ}$ from the surface.

Electrode samples were also characterized using S/TEM. A chemical map was obtained via Electron Energy-Loss Spectroscopy (EELS) in a FEI Osiris S/TEM, operated at $200 \mathrm{kV}$, equipped with a Gatan Enfinium spectrometer.

\section{Results}

Electrochemistry. The representative electrochemistry of a coin cell cycled 60 times is presented in Figure 2. This data took approximately 2.4 months of continuous galvanostatic cycling (constant current rate) to collect. The capacity over 60 cycles is demonstrated in panel (a) and is replotted as a function of cycle index in panel (b), with the lithiation and delithiation endpoints indicated. The difference between the capacity obtained on delithiation and lithiation, termed slippage, ${ }^{33}$ is a measure of lost $\mathrm{Li}^{+}$in the system per cycle. The lithiation endpoint slippage for each cycle is compared to the lithiation capacity for each cycle in panel (c). Selected differential capacity curves are examined in panel (d).

In the first cycle, a lithiation/discharge capacity on the order of the theoretical capacity of $\mathrm{Si}\left(3579 \mathrm{mAhg}^{-1}\right)$ was obtained, the first cycle lithiation capacity being assigned to $100 \%$ State of Health $(\mathrm{SoH})$ (see cycle index 1 in panels a, b, c). Differences from the theoretical capacity of Si are ascribed to mass error and the fast current rate. A delithiation endpoint slippage (difference between discharge and charge capacity) of approximately $760 \mathrm{mAhg}^{-1}$ was accumulated (panel a). This capacity loss indicates $\mathrm{Li}^{+}$being irreversibly consumed in the first cycle, the chemical composition of the electrolyte decomposition products in the SEI at this delithiation endpoint being explored further by ssNMR.

We note that the delithiation/charge profile of the first cycle in panel (a) does not contain the characteristic delithation plateau of the $\mathrm{Li}_{15} \mathrm{Si}_{4}$ phase indicating that this phase was not formed on lithiation. Recent studies have demonstrated that stress, either induced by the presence of a substrate in the case of Si films, ${ }^{34}$ or internal stress in the case of alloys formed with an inactive component, ${ }^{35}$ lowers the voltage at which the $\mathrm{Li}_{15} \mathrm{Si}_{4}$ phase is formed. These two studies suggest that the stresses induced by the inactive $\mathrm{SiO}_{2}$ layer during expansion/contraction of the Si may similarly suppress $\mathrm{Li}_{15} \mathrm{Si}_{4}$ phase formation. However, this phase was observed following a hold step at low voltage combined with a slower cycling rate of $\mathrm{C} / 75$ in our previous study of a binder-free system, ${ }^{23}$ and the electrochemical data of the binder-free system continuously cycled (provided in the Supporting Information Figure S2), clearly shows the formation of this phase in the first few cycles; both results suggest that it is the increased polarization of the composite films that prevents $\mathrm{Li}_{15} \mathrm{Si}_{4}$ formation.

After 30 cycles, the lithiation endpoint was 6116 $\mathrm{mAhg}^{-1}$ (see panels a and b). $\Delta_{1}$, the total irreversible capacity on the interval of cycles $1-30$, is approximately 2558 (6116-3558) $\mathrm{mAhg}^{-1}$. The rate of this capacity loss is seen in panel (c), with the lithiation endpoint slippage of each cycle falling quickly in the first few cycles and then being relatively constant on the interval of cycle index 4 to 30 . The near constant endpoint slippage occurring for each cycle indicates a steady rate of loss of $\mathrm{Li}^{+}$in the system. Higher precision instruments and improved environment control would likely improve the scatter of the data seen here. ${ }^{36}$ Nevertheless, the broad trends of the slippage on the interval are seen. Simultaneously, the lithiation capacity, seen on the right hand axis of panel (c), fell to approximately $50 \%$ SoH by cycle 30.

After 60 cycles, the lithiation endpoint was 7435 $\mathrm{mAhg}^{-1}$ (see panels a and b). $\Delta_{2}$, the total irreversible capacity on the interval of cycles $30-60$, decreases to 1319 (7435-6116) $\mathrm{mAhg}^{-1}$. The ratio $\Delta_{1} / \Delta_{2}$ is approximately 1.9; this ratio was analyzed for 5 samples and varies from approximately $1.7-1.9$, likely due to mass error. The decrease in the total irreversible capacity on the interval $\Delta_{2}$ compared to $\Delta_{1}$ is attributed to the declining slippage trend of $\Delta_{2}$ (see panel c), with the declining slippage indicating decreasing amounts of $\mathrm{Li}^{+}$ being consumed irreversibly. The lithiation capacity continues to decrease on this second interval, reaching $20 \% \mathrm{SoH}$ by cycle 60 .

Representative electrochemical capacity and differential capacity curves in panel (d) provide additional insight. The second cycle shows two processes in the (de)lithiation curves, as expected for amorphous Si systems. ${ }^{8,15,37-39}$ The two discharge/lithiation processes, indicating lithiation of amorphous silicon $(\mathrm{a}-\mathrm{Si}+\mathrm{xLi} \rightarrow$ $\mathrm{a}-\mathrm{Li}_{\mathrm{x}} \mathrm{Si}$ and $\mathrm{a}-\mathrm{Li}_{\mathrm{x}} \mathrm{Si}+\mathrm{x}^{\prime} \mathrm{Li} \rightarrow \mathrm{a}-\mathrm{Li}_{\left(\mathrm{x}+\mathrm{x}^{\prime}\right)} \mathrm{Si}$ with $\mathrm{x}$ and 
(a)

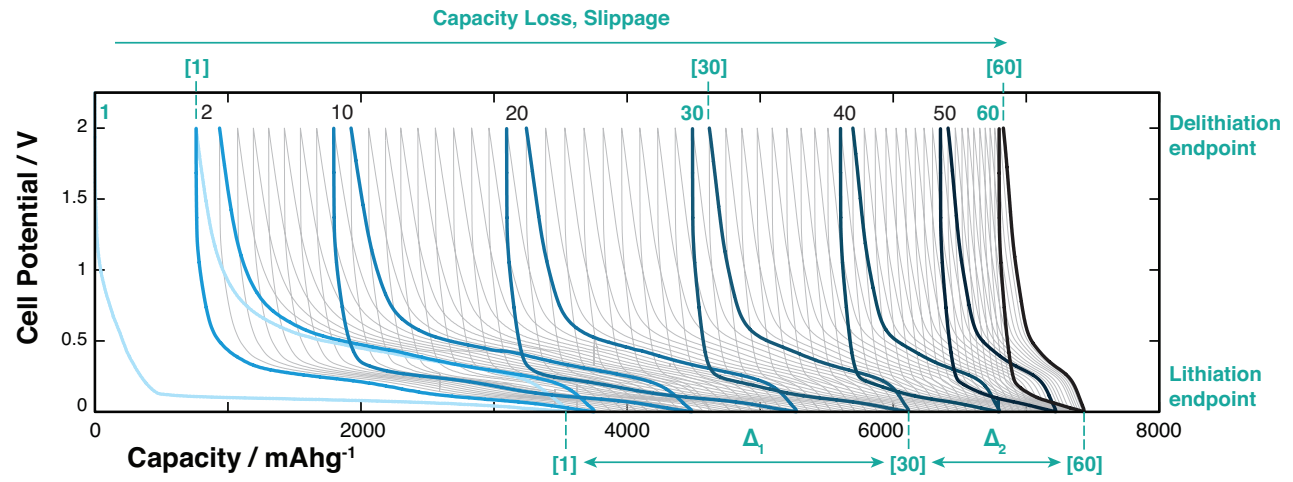

(b)

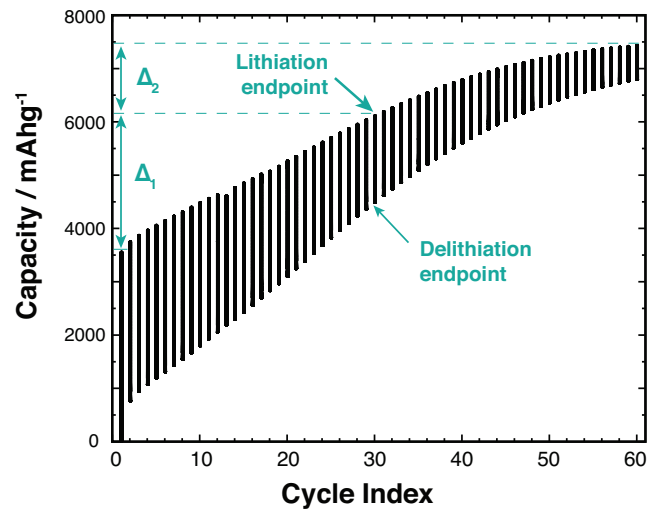

(c)

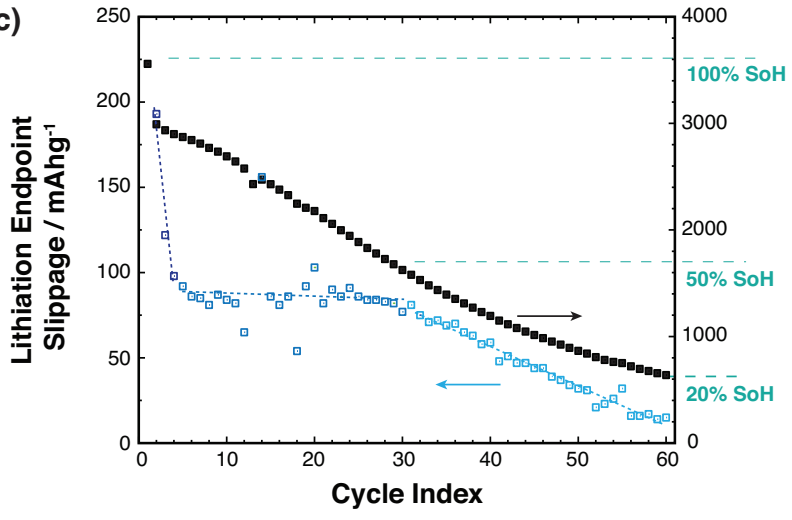

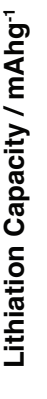

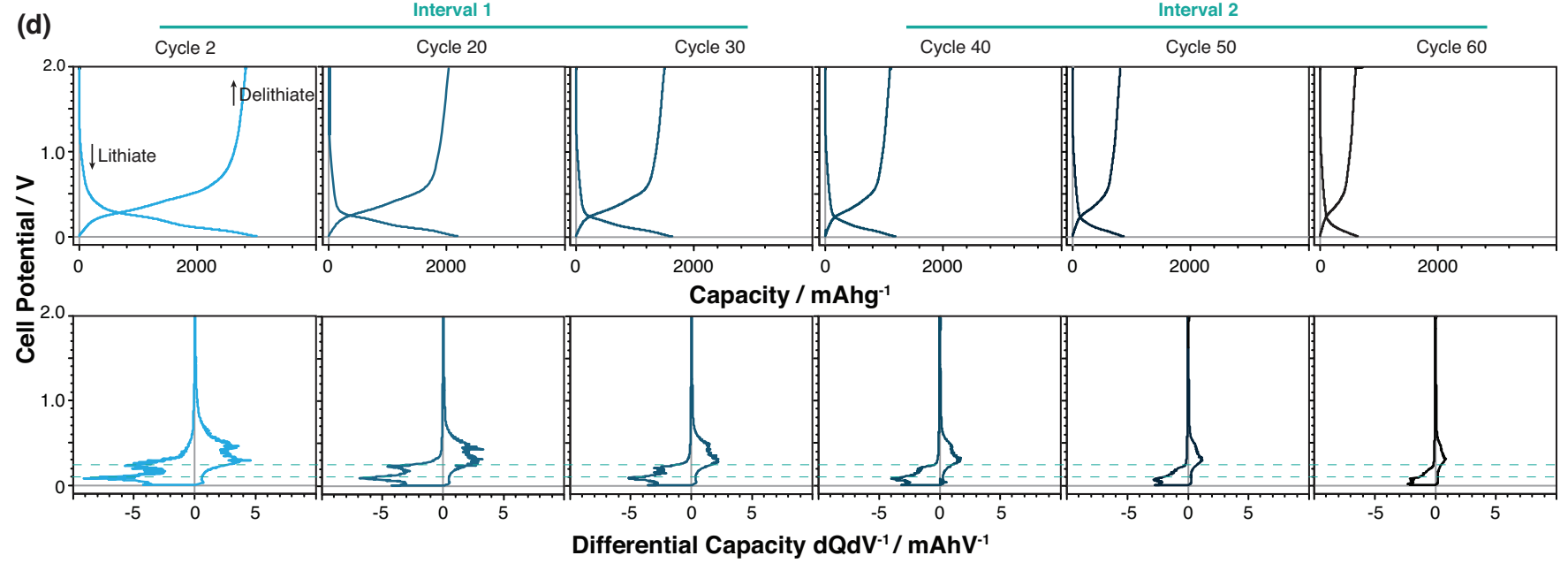

Figure 2: Electrochemical cycling of a Si/C/CMC composite electrode cycled against Li metal and plotted by (a) cell potential vs. capacity and (b) capacity vs. cycle index 1-60. In (c) the slippage (axis left, unfilled points) is compared to the lithiation/discharge capacity (axis right, filled points) for each cycle index. The slippage is approximated by three regions, indicated by linear fits. The lithiation endpoint slippage is defined as the difference of the lithiation endpoints for incremental cycles and is a measure of irreversibly consumed $\mathrm{Li}^{+}$in the system per cycle. $\Delta_{1}$ and $\Delta_{2}$ indicate the total irreversible capacity between cycles 1-30 and 30-60, respectively. In (d) selected capacity and differential capacity $d Q d V^{-1}$ curves for cycle 2-60 are presented, showing the detail of the lithiation/delithiation processes of the Si electrochemistry. Cycles 2-30 and 30-60 are labelled interval 1 and 2, respectively. Dashed lines indicate the initial potential of the electrochemical lithiation processes, occurring at approximately 250 and $100 \mathrm{mV}$.

$\mathrm{x}$ ' having values of approximately 2.0 and 1.5$),{ }^{15,38}$ initially occur at approximately $250 \mathrm{mV}$ and $100 \mathrm{mV}$. Based on our previous work, ${ }^{10,38,39}$ the higher voltage process $(250 \mathrm{mV})$ corresponds to the initial lithiation of amorphous Si and subsequent breaking apart of the amorphous Si into large Si clusters by the Li insertion. The lower voltage process $(100 \mathrm{mV})$ corresponds to further Li reaction with the increasingly smaller Si clusters, e.g., Si-Si dimers, eventually resulting in only isolated $\mathrm{Si}$ anions at approximately $\left(\mathrm{Li}_{3.5} \mathrm{Si}\right)$. Between cycle 20 and cycle 30 the intensity of the high voltage (250 $\mathrm{mV}$ ) peak in the differential capacity plots becomes less pronounced and by cycle 40 is barely visible (indicated by the top dashed line in panel d). Interestingly, the decreased intensity of this high voltage process is seen for both the lithiation and delithiation (discharge and charge) showing that this change is symmetric.

The electrochemical profiles are approximated by two intervals, cycles $2-30(100-50 \% \mathrm{SoH})$ and cycles 30 - $60(50-20 \% \mathrm{SoH})$. In the first interval, all the Si lithiation processes are evident, and $\mathrm{Li}^{+}$is irreversibly consumed at a steady rate. In the second interval, the Si lithiation processes are less evident, and less irreversible capacity is accumulated. The decreasing rate of $\mathrm{Li}^{+}$being irreversibly consumed is correlated with a decreasing amount of lithiation of the Si particles in the 

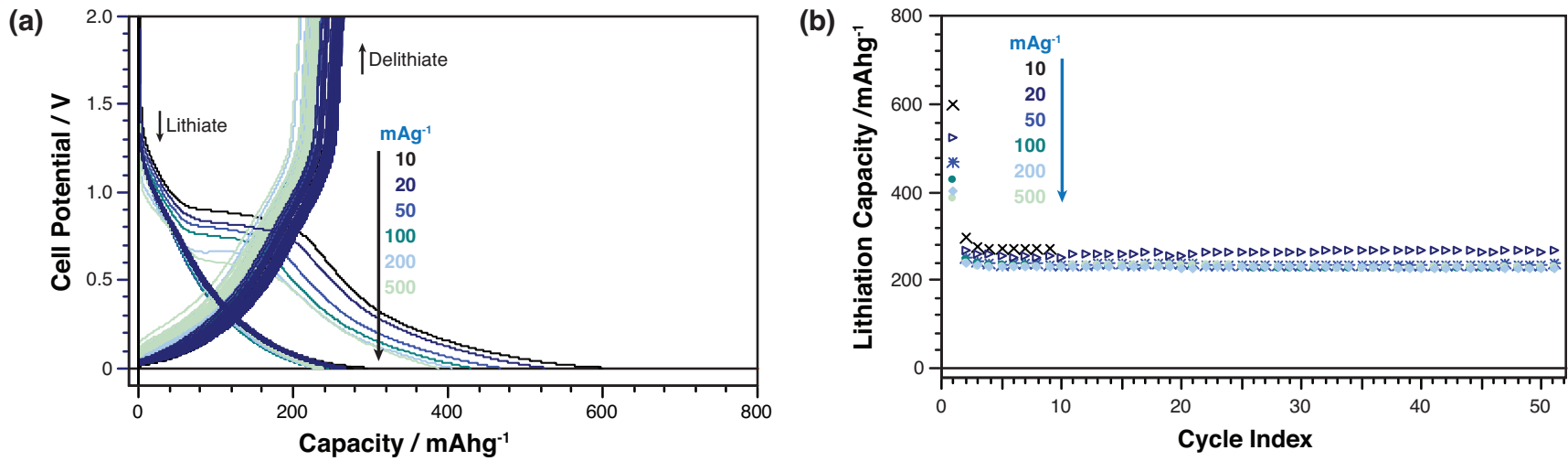

Figure 3: Electrochemical cycling of 6 coin cells with C SuperP powder electrodes cycled against Li metal. Capacities at constant currents of $10,20,50,100,200$, and $500 \mathrm{mAg}^{-1}$ were compared for 50 cycles plotted in (a) cell potential vs. capacity (reset to 0 for each cycle) and (b) discharge capacity vs. cycle index. The result of (a) shows that the increasing current density correlates with a decrease in the voltage, from approximately 0.9 down to $0.6 \mathrm{~V}$, of the first electrolyte decomposition process. The result of (b) shows that the increasing current density correlates with a decreasing discharge capacity on the first cycle and stable capacity retention (in the absence of $\mathrm{Si}$ ) from cycle 2 to 50.

system, and thus both the reduced volume expansion of the electrode and the time the electrode spends at low potentials.

Additional experiments were performed to explore the cell failure further. In the first experiment (see Supporting Information, Figures S4 and S5), an electrode sample was cycled for 60 cycles at a constant current rate of $\mathrm{C} / 30$ and then the current rate was reduced by a factor of 10 to $\mathrm{C} / 300$. The experiment showed a recovery of lost lithiation capacity at the slow current rate and the high voltage lithiation/delithiation processes reappeared. These results suggest that kinetics are a clear factor contributing to the lithiation capacity fade. In a second experiment, a cell was stopped at the lithiation endpoint on cycle 60 and disassembled to confirm that sufficient Li metal was available and that the separator was still soaked with electrolyte. Contributions from surface effects on the Li metal to slippage and discharge capacity loss cannot be ruled out, but they cause slippage in the opposite direction.

To characterize the lithiation capacity relating to the conductive $\mathrm{C}$ in the system, $6 \mathrm{C}$ SuperP electrodes were cycled against Li metal in coin cells with current densities from 10 to $500 \mathrm{mAg}^{-1}$ (Figure 3). An initial lithiation capacity up to $\sim 600 \mathrm{mAhg}^{-1}$ was obtained at the lowest current of $10 \mathrm{mAg}^{-1}$, dropping to $\sim 400 \mathrm{mAhg}^{-1}$ at the highest current of $500 \mathrm{mAg}^{-1}$ (compared to $\mathrm{C} / 30$ and $119 \mathrm{mAhg}-1$ for the composite Si electrodes). The decreasing potential of the pseudo plateau in the first cycle is clearly a polarization effect. With a C SuperP:Si 1:1 mixture in the composite electrode system, approximately $400 \mathrm{mAhg}^{-1}$ of the capacity in the first cycle is attributed to the presence of C SuperP. An irreversible capacity in the first cycle of almost $200 \mathrm{mAhg}^{-1}$ (see Supporting Information, Figure S3) is likely due to SEI formation on conductive $\mathrm{C}$ surfaces. Note that this approximation does not take into account the effects of the binder or electrode formulation. Clearly, the expansion of $\mathrm{Si}$ and the composite electrode formulation would have an impact on the capacity retention relating to the conductive $\mathrm{C}$ in the system. But in the absence of $\mathrm{Si}$, a stable lithiation capacity from the C-only elec- trodes of approximately $\sim 230 \mathrm{mAhg}^{-1}$ was measured.

SEI Growth Measured by ssNMR. With the capacity loss observed by electrochemistry, the corresponding SEI growth was monitored using ssNMR on samples prepared at the delithiation point after cycle 1,30 , and 60. Quantitative signal intensities were obtained by performing direct excitation ${ }^{13} \mathrm{C},{ }^{7} \mathrm{Li}$, and ${ }^{19} \mathrm{~F}$ ssNMR experiments (Figure 4) for each of the ${ }^{13} \mathrm{C}$ labelled EC and DMC sample sets. Each of the samples consist of 2-4 individual electrode samples, which were combined for the ssNMR experiments; any minor variations between cycled electrode samples are therefore averaged. The experimental data and analysis presented here are supported by detailed analysis and additional ssNMR spectra, available in the Supporting Information: experiments with varying MAS rates confirm the position of the ssNMR spinning side bands (indicated by asterisks in Figure 4), while control measurements on the CMC binder and pristine electrode material confirm the chemical shifts of carbon functional groups that are attributed to the electrode material rather than to the SEI.

${ }^{19} \mathrm{~F}$ ssNMR: The ${ }^{19} \mathrm{~F}$ ssNMR results show resonances assigned to $\mathrm{LiF}$ (-204 ppm) and residual $\mathrm{LiPF}_{6}(-73$ $\mathrm{ppm}$ ) in the system (Figure 4). In the cycle 1 and 30 ${ }^{13} \mathrm{C}$-labelled EC samples, sharp resonances are seen at -84 and $-122 \mathrm{ppm}$. The $-84 \mathrm{ppm}$ resonance is assigned to $\mathrm{PO}_{\mathrm{x}} \mathrm{F}_{\mathrm{y}}$ species such as $\mathrm{Li}_{\mathrm{x}} \mathrm{POF}_{\mathrm{y}}$, these species being formed by reactions with $\mathrm{H}_{2} \mathrm{O}$ and $\mathrm{PF}_{\mathrm{x}}$ decomposition products of $\mathrm{LiPF}_{6} \cdot{ }^{40}$ The $-122 \mathrm{ppm}$ resonance has a chemical shift in the range of $\mathrm{SiO}_{\mathrm{x}}, \mathrm{F}_{\mathrm{y}}$, species, ${ }^{41}$ such species having been detected on the surfaces of Si by Philippe et al. using photoelectron spectroscopy. ${ }^{42}$ The presence of $\mathrm{F}-\mathrm{C}$ bonds, also resonating in this region of the ${ }^{19} \mathrm{~F}$ spectra, were ruled out by ${ }^{19} \mathrm{~F}-{ }^{13} \mathrm{C} \mathrm{CP}$ experiments (see Supporting Information). The amount of $\mathrm{LiF}$ (indicated by the integrated intensity of the -204 ppm peak) does not increase significantly after the first cycle, suggesting that LiF is formed primarily in the initial cycle. The amount of residual $\mathrm{LiPF}_{6}$ salt varies between the samples, with an increased amount of resid- 

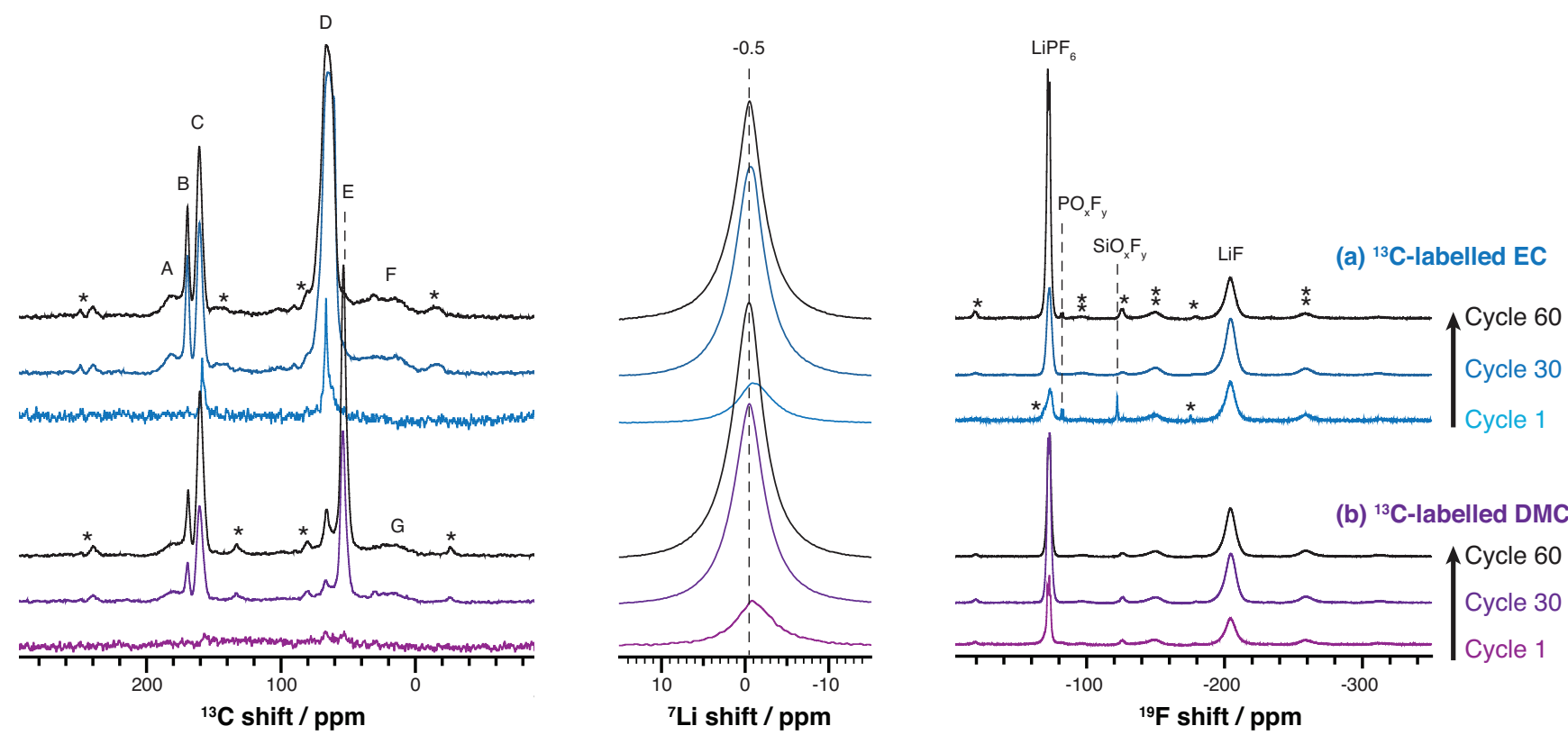

Figure 4: Direct excitation ${ }^{13} \mathrm{C},{ }^{7} \mathrm{Li}$, and ${ }^{19} \mathrm{~F}$ ssNMR experiments of electrode samples prepared with (a) ${ }^{13} \mathrm{C}$ EC (blue) and (b) ${ }^{13} \mathrm{C}$ DMC (purple) labelled electrolytes. Measurements were performed on electrode samples from coin cells cycled through 1, 30, and 60 electrochemical cycles (approximately 100,50,20\% SoH). Single pulse ${ }^{13} \mathrm{C}$ and Hahn echo ${ }^{19} \mathrm{~F}$ spectra were acquired on a $500 \mathrm{MHz}$ spectrometer with 10 $\mathrm{kHz}$ and $25 \mathrm{kHz}$ MAS rate, respectively. ${ }^{7} \mathrm{Li}$ single pulse spectra were acquired on a $400 \mathrm{MHz}$ spectrometer with $30 \mathrm{kHz}$ MAS rate. ${ }^{13} \mathrm{C}$ peak assignments $A-G$ are summarized in Table 1 . Asterisks indicate spinning sidebands.

ual $\mathrm{LiPF}_{6}$ salt being seen after the first cycle in each of the ${ }^{13} \mathrm{C}$-labelled EC and DMC sample sets. The results are consistent with $\mathrm{LiPF}_{6}$ salt being trapped in the SEI, the thickness of the SEI layer increasing during cycling. An evolving pore structure may also trap more residual electrolyte.

${ }^{7} \mathrm{Li}$ ssNMR: The overall ${ }^{7} \mathrm{Li}$ signal intensity increases with cycle number in both sample sets, the most pronounced increase occurring in the first 30 cycles (Figure 4). After the first cycle, the broad ${ }^{7} \mathrm{Li}$ resonance is centred at approximately $-1.0 \mathrm{ppm}$ (the chemical shift of $\mathrm{LiF}$ ) and after subsequent cycles the resonance shifts to approximately $-0.5 \mathrm{ppm}$. The broad $-0.5 \mathrm{ppm}$ resonance is assigned to $\mathrm{Li}$ salts including $\mathrm{LiF}(-1.0 \mathrm{ppm}), \mathrm{Li}_{2} \mathrm{CO}_{3}$ (0.0 ppm), $\mathrm{ROCO}_{2} \mathrm{Li}, \mathrm{LiPF}_{6}$ (-2.9 ppm), and possibly $\mathrm{Li}_{4} \mathrm{SiO}_{4}(1.2 \mathrm{ppm}) .{ }^{43-45}$ The low resolution of the ${ }^{7} \mathrm{Li}$ ssNMR spectra impedes accurate deconvolution of the $\mathrm{Li}$ salt environments. However, these ${ }^{7} \mathrm{Li}$ assignments are supported by the ${ }^{19} \mathrm{~F}$ and ${ }^{13} \mathrm{C}$ ssNMR spectra which have a much larger chemical shift dispersion.

${ }^{13} \mathrm{CssNMR}$ : The growth of the organics of the SEI is evident by the increasing signal intensities seen in the spectra in Figure 4, between cycle 1 and cycle 30, the ${ }^{13} \mathrm{C}$ resonances in each of the ${ }^{13} \mathrm{C}$-labelled $\mathrm{EC}$ and DMC samples being labelled $\mathrm{A}-\mathrm{G}$. The organic SEI composition is further investigated by $2 \mathrm{D}{ }^{13} \mathrm{C}$ homonuclear (INADEQUATE) ${ }^{28-31}$ ssNMR and cross polarization ssNMR experiments in Figures 5 and 6 . Any residual $\mathrm{EC}$ remaining in the electrodes is not observable in the $2 \mathrm{D}{ }^{13} \mathrm{C}$ INADEQUATE ssNMR experiment of Figure 5 as the $\mathrm{CH}_{2}{ }^{13} \mathrm{C}$ nuclei are magnetically equivalent. For each of the samples, similar environments are observed in the carbonate and carboxyl region (A, B, C). The overlapping resonances contributing to $\mathrm{D} / \mathrm{F}$ and $\mathrm{E} / \mathrm{G}$ are characteristic of EC and DMC decomposition products, respectively. ${ }^{23}$ The integrated signal intensity between the 30 and 60 cycles is approximately equal, with quantitative error arising from residual electrolyte, and differences in the sample mass packed inside the ssNMR rotors. An additional error may arise from the undesired removal of a small fraction of the SEI at the surface of the electrode, which may adhere to the separator instead of the electrode when they are physically separated during battery disassembly. A deconvolution analysis was performed for a more quantitative comparison (see Supporting Information, Table S1). To improve accuracy, the Gaussian fits corresponding to resonances $\mathrm{C}, \mathrm{D}$, and $\mathrm{E}$, were excluded from the integrated signal intensity, thereby removing any error arising from residual EC and DMC (the assignments are discussed further, see Table 1). The ratios of the integrated signal

Table 1: Summary of ${ }^{13} \mathrm{C}$ ssNMR assignment of carbon functionalities $A-G$ in Figures 4-6. Specific R-groups are suggested where possible. The assignments in Table 1 are based on our previous assignments. ${ }^{23}$

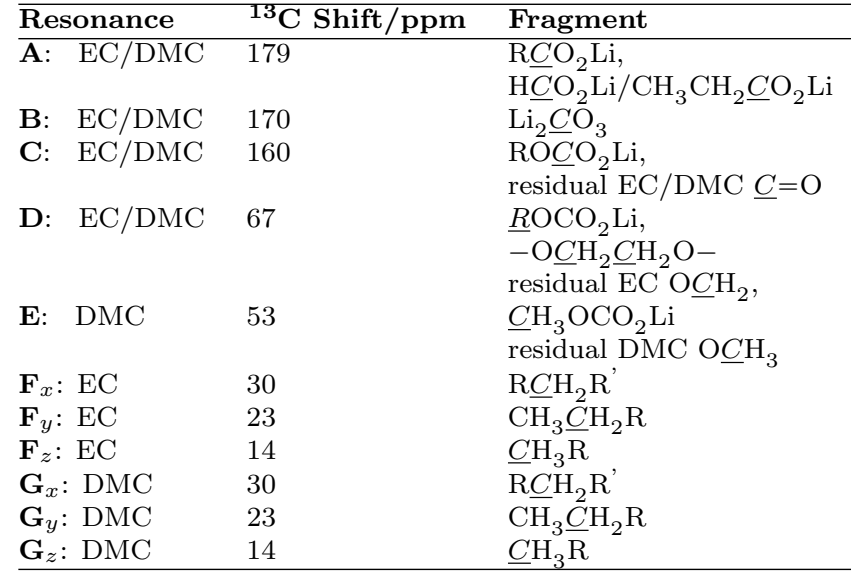

intensities of the samples at cycle $60 /$ cycle 30 of 1.2 and 
1.1 were found for the ${ }^{13} \mathrm{C}$-labelled DMC and EC samples, respectively, indicating that while the majority of SEI growth has already occurred by cycle $30(50 \% \mathrm{SoH}$, Figure 2-b) in these samples, there is a minor growth of $10-20 \%$ of the organics in the SEI. This is noticeably less than might be expected from the analysis of the endpoint slippages $\Delta_{1} / \Delta_{2}$ (Figure 2-b) where an average ratio of 1.7-1.9 was found, which would translate into an increase in the integrated signal intensities on the order of $50-60 \%$ if all the irreversible capacity loss would have resulted in the formation of a solid SEI. Furthermore, no new chemical environments are detected between 30 and 60 cycles, in any of the ${ }^{19} \mathrm{~F},{ }^{7} \mathrm{Li}$, or ${ }^{13} \mathrm{C}$ ssNMR spectra. The result suggests that additional factors beyond SEI growth contribute to the endpoint slippage. For example, soluble SEI products contained in the electrolyte are not accounted for in the ssNMR result here, the solubility of the SEI having been investigated by others. ${ }^{46}$ It is also worth noting that if the SEI increasingly forms at the surface of the electrode, then any error induced by SEI adhering to the separator would decrease the signal intensity of the cycle 60 sample more than the cycle 30 sample.

The large chemical shift dispersion of the ${ }^{13} \mathrm{C}$ spectra allows for definitive assignment of the carbon functional groups present in the 30 and 60 cycle samples. The ${ }^{13} \mathrm{C}$ NMR spectra strongly resemble that of our previous study of the SEI composition of a binderfree system after 1 cycle. The carboxyl resonance A (179 ppm) indicates an $\mathrm{R}_{\underline{C}} \mathrm{O}_{2} \mathrm{Li}$ environment. While additional species cannot be ruled out, $\mathrm{HCO}_{2} \mathrm{Li}$ and $\mathrm{CH}_{3} \mathrm{CH}_{2} \mathrm{CO}_{2} \mathrm{Li}$ represent the most likely species; the presence of $\mathrm{HCO}_{2} \mathrm{Li}$ was confirmed by ${ }^{1} \mathrm{H}$ NMR (see Supporting Information, Figure S13). The carbonate resonance $\mathrm{B}(170 \mathrm{ppm})$ is assigned to $\mathrm{Li}_{2} \underline{\mathrm{CO}_{3}}$ based on its distinctive chemical shift. The distribution of carbonate environments giving rise to the peak labelled $\mathrm{C}$ (160 ppm) includes $\mathrm{ROCO}_{2} \mathrm{Li}$ decomposition products, and some minor contribution from the carbonate environments of residual EC and DMC. The distribution of $\mathrm{sp}^{3}$ carbons contributing to resonance $\mathrm{D}(67 \mathrm{ppm})$ are characteristic of $\underline{R} \mathrm{OCO}_{2} \mathrm{Li}$ and $-\mathrm{O}_{\underline{C}} \mathrm{H}_{2} \underline{C} \mathrm{H}_{2} \mathrm{O}-$ oligomer environments, expected decomposition products of EC. Some minor contribution from residual EC $\mathrm{O}_{\underline{C}} \mathrm{H}_{2}$ groups $(67 \mathrm{ppm})$ also contribute to $\mathrm{D}$. The resonance labelled $\mathrm{E}$ is assigned to $\mathrm{CH}_{3} \mathrm{OCO}_{2} \mathrm{Li}$, lithium methyl carbonate (LMC), with some minor contribution from residual $\mathrm{DMC} \mathrm{OCH}_{3}$ groups. The resonances labelled $\mathrm{F}$ and $\mathrm{G}(0-50 \mathrm{ppm})$ have chemical shifts characteristic of $\mathrm{CH}_{3}$ and $\mathrm{CH}_{2}$ environments which are not adjacent to $\mathrm{O}$ atoms. Furthermore, the very broad line shape of resonances $\mathrm{F}$ and $\mathrm{G}$ are a clear signature of amorphous/disordered environments. The distribution of environments are approximately described by three representative shifts of 30,23 , and $14 \mathrm{ppm}$ (labelled by subscripts $\mathrm{x}, \mathrm{y}, \mathrm{z}$ in Figures 5 -b and 6 -ii). In previous work, we explored chemical shift trends of expected SEI molecules using DFT calculations. ${ }^{23}$ Based on our initial NMR chemical shift map of the organ- (a)

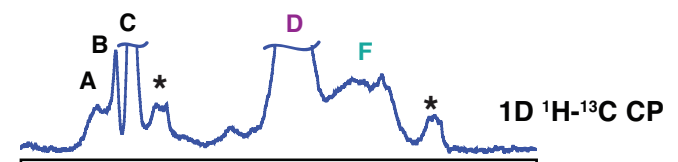

(b)
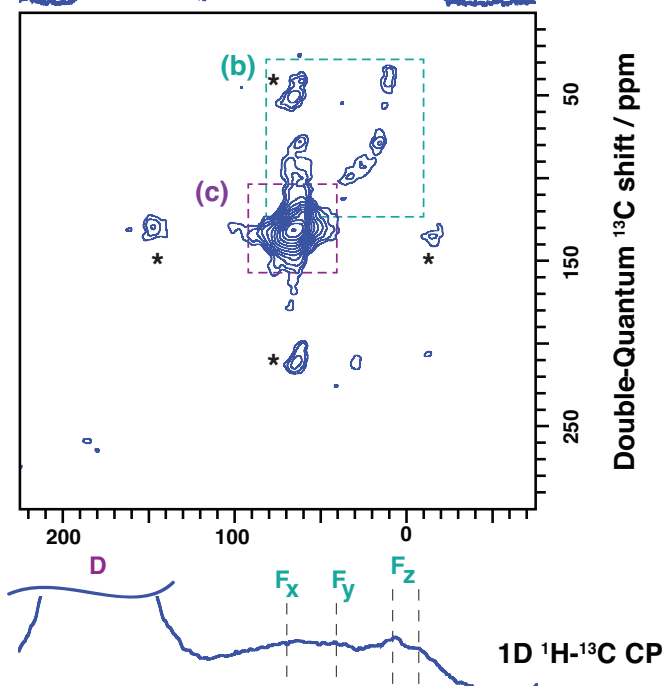

(c)
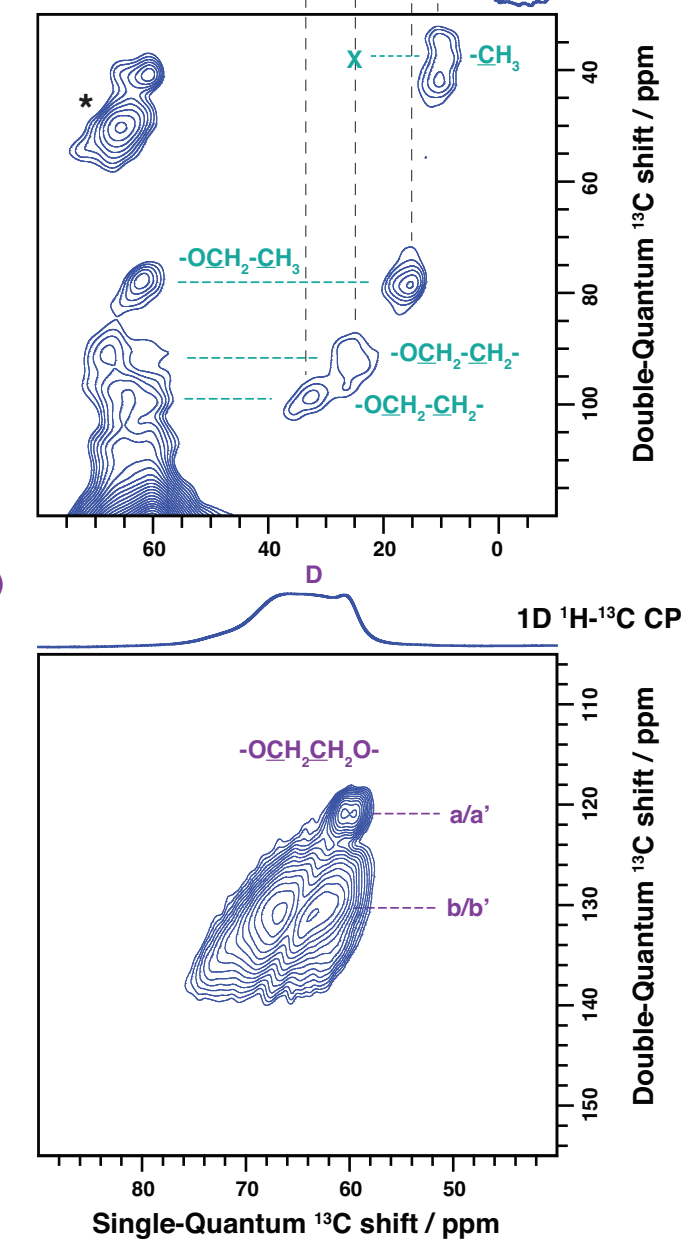

Figure 5: ${ }^{13} \mathrm{C} D Q / S Q$ homonuclear correlation ssNMR experiment performed on the 30 cycle sample prepared with ${ }^{13} \mathrm{C}$-labelled $\mathrm{EC}$ electrolyte. The correlations in the J-based ${ }^{1} \mathrm{H}-{ }^{13} \mathrm{C} \mathrm{CP}$ refocused INADEQUATE experiment show the pairs of resonances which are bonded. See Supporting Information for views of the spectra with lower contour levels. Asterisks indicate spinning sidebands.

ics in the SEI we expect $\underline{C} \mathrm{H}_{3} \mathrm{R}$ environments, present in SEI molecules such as $\mathrm{RCO}_{2} \mathrm{Li}$, to resonate at lower chemical shifts of approximately $15 \mathrm{ppm} . \mathrm{CH}_{3} \underline{\mathrm{C}} \mathrm{H}_{2} \mathrm{R}$ environments are expected to resonate at higher shifts 

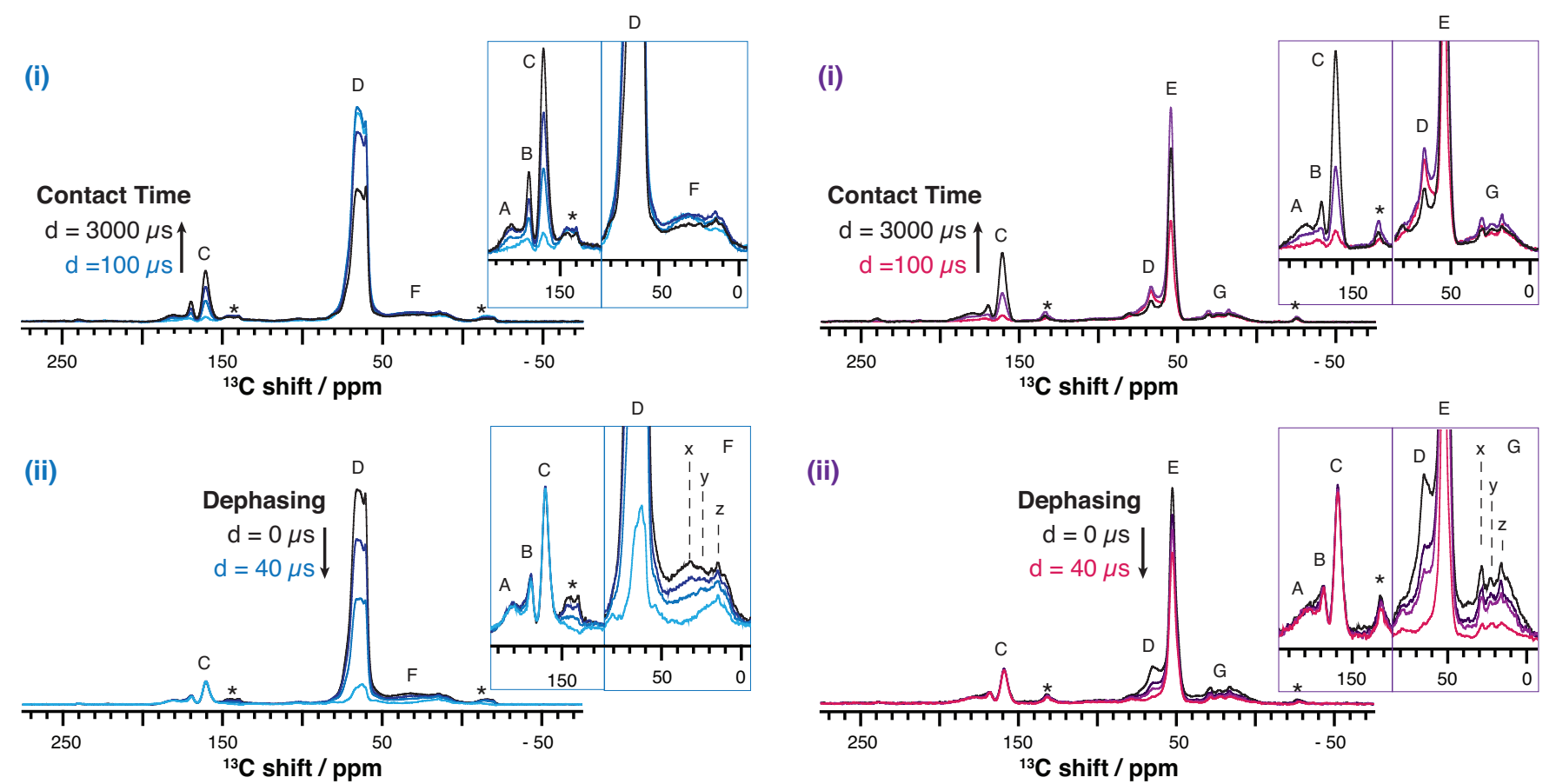

(a) ${ }^{13} \mathrm{C}$-labelled EC Samples

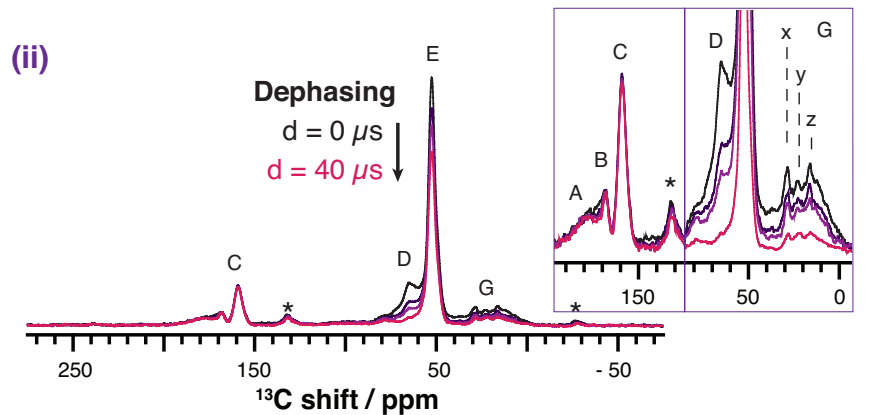

(b) ${ }^{13}$ C-labelled DMC Samples

Figure 6: ssNMR ${ }^{1} \mathrm{H}_{-}{ }^{13} \mathrm{C}$ cross polarization and dephasing experiments of electrode samples prepared with (a, left) ${ }^{13} \mathrm{C}$ EC and (b, right) ${ }^{13} \mathrm{C}$ DMC labelled electrolytes. When delay times are varied in the experiment, different $C$ functional groups can be identified based on their attenuation rates. In (a-i, b-i) CP contact times in the experiments were varied and in (ii-a, ii-b) dephasing times were varied. See Supporting Information for ssNMR pulse sequence details. Increasing CP contact times of (a-i) 100, 500, 1000, $3000 \mu \mathrm{s}$ and (b-i) 100, 500, $3000 \mu \mathrm{s}$ correlate with increasing carbonate and carboxyl signal intensities. Using a fixed CP contact time of $500 \mu$ s, increasing dephasing times of (a-ii) $0,10,15,40 \mu \mathrm{s}$ and (b-ii) $0,15,20,30 \mu$ s correlate with decreasing signal intensities of proton-bonded carbons. Asterisks indicate spinning sidebands.

of approximately 20 ppm. R' $\underline{\mathrm{C}} \mathrm{H}_{2} \mathrm{R}$ environments, present in molecules such as lithium butylene dicarbonate (LBDC), are expected to resonate at higher shifts of approximately 25-30 ppm. However, we note many molecules or fragments may form and contribute to the signal in this region.

SEI Organic Composition, ${ }^{13} \mathrm{C} s s N M R$ : The region of the ssNMR spectra of resonances D-G are of interest in determining the length and composition of the alkyl chains of the SEI organics. These environments were examined using a $2 \mathrm{D}{ }^{13} \mathrm{C}$ homonuclear experiment (INADEQUATE). ${ }^{28-31}$ This experiment shows correlations between directly bonded ${ }^{13} \mathrm{C}$ resonances with different chemical shifts and excludes all non-bonded ${ }^{13} \mathrm{C}$ resonances. The result of the experiment performed on the 30 -cycle ${ }^{13} \mathrm{C}$-labelled EC sample is shown in Figure 5. With the $\mathrm{CH}_{2}$ groups of EC being magnetically equivalent, any detection of residual EC is excluded. The complementary 2D ssNMR experiment performed on the ${ }^{13} \mathrm{C}$-labelled $\mathrm{DMC}$ sample is contained in the Supporting Information, Figure S8.

Figure 5 panel (a) shows the overall spectrum showing correlations involving $\mathrm{OCH}_{2}$ (resonance D) and $\mathrm{CH}_{2} / \mathrm{CH}_{3}$ (resonance $\mathrm{F}$ ) groups. Panel (b) shows an expansion of part of the spectrum, more clearly showing these $\mathrm{D}-\mathrm{F}$ correlations. While many correlations might be expected, only the unambiguous correlations are labelled. These correlations correspond to $\mathrm{OCH}_{2}$ resonances $\mathrm{D}$ bonded with $\mathrm{F}_{\mathrm{x}}\left(\mathrm{CH}_{2}, 30 \mathrm{ppm}\right), \mathrm{F}_{\mathrm{y}}\left(\mathrm{CH}_{2}\right.$, $23 \mathrm{ppm})$, and $\mathrm{F}_{\mathrm{z}}\left(\mathrm{CH}_{3}, 14 \mathrm{ppm}\right)$. An additional $\mathrm{CH}_{3}$ correlation is also seen at $10 \mathrm{ppm}$ and based on its double-quantum frequency is expected to correlate with a $\mathrm{CH}_{2}$ group (23 ppm), (indicated by a dashed line and "X"). The lack of signal in the $23 \mathrm{ppm}\left(\mathrm{CH}_{2}\right)$ region is tentatively ascribed to the faster dephasing and subsequent signal loss during the ssNMR pulse sequence of a $\mathrm{CH}_{2}$ group vs. a $\mathrm{CH}_{3}$ group. These bonded environments are present in SEI decomposition products such as $\mathrm{LBDC}, \mathrm{RCO}_{2} \mathrm{Li}$, and lithium ethylene carbonate (LEC). The detection of these correlations is limited by the inherent sensitivity of the experiment and additional correlations are likely to be present: views of panels (a) and (b) with lower contour levels are presented in the Supporting Information, Figure S9, showing these additional correlations. Panel (c) is an expansion of the resonance $\mathrm{D}$ region, showing correlations between different $\mathrm{CH}_{2} \mathrm{O}$ groups. The correlations clearly indicate at least two $-\mathrm{OCH}_{2} \mathrm{CH}_{2} \mathrm{O}-$ fragments corresponding to $\mathrm{C}$ pairs within different molecules or within the same molecule, separated from the rest of the alkyl chain by an $\mathrm{O}$. These fragments are contained in PEO-type oligomers, and lithium alkyl carbonates.

The nature of the different environments were more rigorously investigated using ${ }^{1} \mathrm{H}-{ }^{13} \mathrm{C}$ cross polarization (CP) ssNMR experiments (Figure 6), with the signal intensity in these experiments depending on molecular dynamics, mobility, and spatial proximity of ${ }^{1} \mathrm{H}$ and ${ }^{13} \mathrm{C}$ nuclei. In one set of experiments (a-i, b-i) the CP contact time in the experiment was varied, showing an increasing signal intensity in the carbonate and carboxyl 
region of the spectra (resonances $\mathrm{A}, \mathrm{B}, \mathrm{C}$ ) with increasing $\mathrm{CP}$ contact time (see inset, left). In contrast, the environments labelled $\mathrm{D}$ and $\mathrm{E}$ begin to attenuate in the experiment, due to signal loss during the longer CP contact times (due to shorter dephasing times of the spinlocked magnetization in the CP pulse sequence, defined by the NMR parameter $\left.T_{1 \rho}\right)$. The maximum signal intensity of D and E are observed at 500 ps. By 3000 us the signal intensities of D are attenuated to approximately $50 \%$ of the signal intensity maximum, and the overlapping resonances labelled $\mathrm{E}$ is attenuated to approximately $75 \%$ of the signal intensity maximum. This observed behaviour is characteristic of $\mathrm{CH}_{2}$ and $\mathrm{CH}_{3}$ environments, respectively. Overlapping resonances labelled $\mathrm{F}$ and $\mathrm{G}$ also show some minor attenuation.

In a second set of experiments (a-ii, b-ii) a delay was introduced, following the cross polarization step in the experiment, to perform a dipolar dephasing (interrupted decoupling) experiment (see Supporting Information for experimental details). This experiment allows protonated and non-protonated environments to be differentiated, the signal intensities of the $\mathrm{CH}$ and $\mathrm{CH}_{2}$ groups attenuating more rapidly in comparison to the signals from non-protonated carbon. Mobility of the $\mathrm{CH}_{\mathrm{x}}$ environments is also probed, with rigid $\mathrm{CH} / \mathrm{CH}_{2}$ environments attenuating more rapidly than signal from mobile species such as rotating $\mathrm{CH}_{3}$ methyl groups (due to a reduced dipolar coupling). Note that the dephasing times differ slightly between the two samples (a, b) and that the broad resonances $\mathrm{F}$ and $\mathrm{G}$ are visually skewed by the overlapping dephasing of $\mathrm{D}$ and $\mathrm{E}$ (in each of a-ii, b-ii). The carboxyl and carbonate resonances A, B, C, which do not have directly bonded protons, are not attenuated in the experiment (see inset, left). In contrast, the overlapping resonances of D show a pronounced attenuation with increasing dephasing times in each of the experiments, characteristic of $\mathrm{CH}_{2}$ functional groups (see inset, right): by $15 \mu \mathrm{s}$ dephasing delay in each of the samples, D is attenuated to approximately $50 \%$ of its maximum signal intensity. Resonance $\mathrm{E}$ shows less rapid attenuation than $\mathrm{D}$, characteristic of $\mathrm{CH}_{3}$ functional groups, dropping to only approximately $80 \%$ of its maximum signal intensity following a $15 \mu$ s dephasing delay in the ${ }^{13} \mathrm{C}$-labelled DMC sample. Additionally, the dephasing experiments confirm multiple environments in the $0-50 \mathrm{ppm}$ range. Within the broad resonances $\mathrm{F}$ and $\mathrm{G}$, the environments with higher chemical shifts, $\mathrm{F}_{\mathrm{x}} / \mathrm{G}_{\mathrm{x}}(30 \mathrm{ppm})$, attenuate the most rapidly, characteristic of $\mathrm{CH}_{2}$ functional groups (marginally slower than D). The environments with a lower chemical shift, $\mathrm{F}_{\mathrm{z}} / \mathrm{G}_{\mathrm{z}}(14 \mathrm{ppm})$ attenuate the least rapidly, characteristic of $\mathrm{CH}_{3}$ functional groups (comparable to E). Covalent bonding with the $\mathrm{C}$ functional groups seen in the dephasing experiment were confirmed in the ${ }^{13} \mathrm{C}$ homonuclear correlation ssNMR experiment (Figure 5).

Surface \& Pore Structure Analysis. Analysis of the electrode surfaces before and after cycling shows evidence of mechanical failure, with electrode cracking of

the films being seen at different length scales, from $\sim 100$ $\mu \mathrm{m}$ down to $\sim 1 \mu \mathrm{m}$, Figure 7 . The cracking is likely due to the large Si expansion and contraction during cycling.

(a) PRISTINE

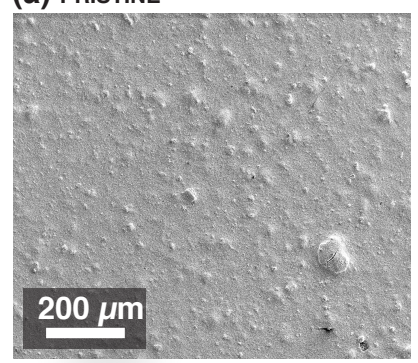

(b) CYCLED
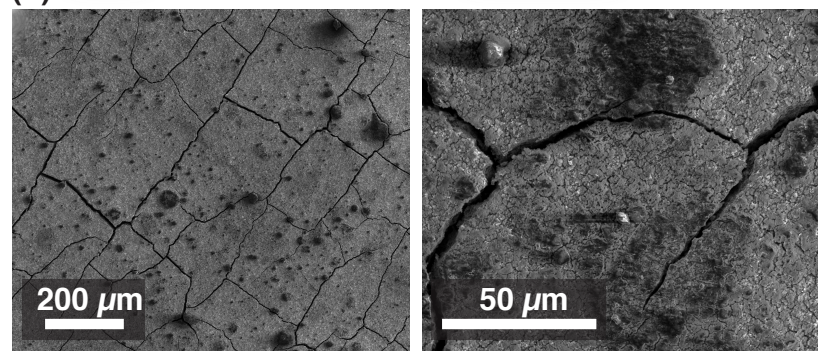

Figure 7: SEM micro images of a (a) pristine uncycled electrode and (b) cycled electrode sample, after 60 electrochemical cycles.

SEM views of FIB cross sections show the changing pore structure of the electrode after electrochemical cycling, Figure 8. The initial structure of the pristine electrode, before cycling and assembly, has a relatively low density, with roughly spherical pores, starting in size from a few tens of nm, between $\mathrm{Si}$ and $\mathrm{C}$ particles, panel (a). After one electrochemical cycle, panel (b), the electrode displays a higher density due to some aggregation of particles into larger solid structures; fewer small, spherical pores are observed, and larger voids dominate the overall pore morphology. A control experiment confirmed no structural change was caused by the residual electrolyte and assembly into a coin cell; see the Supporting Information for a comparison of an electrode sample that was assembled and wet with electrolyte, compared to the pristine electrode sample that was neither assembled nor wet with electrolyte. By 30 and 60 cycles, panels (c) and (d), the electrode has a much higher density, with further agglomeration of particles. Some very large voids, up to several hundreds of microns, are still visible, but the overall structure is considerably more compact than in the pristine case. The 60 cycle sample shows some larger voids than the 30 cycle sample and evidence of more pore clogging. However, the overall microstructure of the 30- and 60-cycle samples are very similar within the error and sampling statistics of the experiments. The similar pore structures observed by FIB/SEM for the 30- and 60-cycle samples are in agreement with the ssNMR results, which detect similar quantities of SEI on the same interval.

The electrode sample at cycle 60 was examined at higher resolution. An analysis region is indicated in panel (e), centred on a large void in the electrode sample, which may have formed due to a gas bubble formed during the electrode preparation. The void allows for 

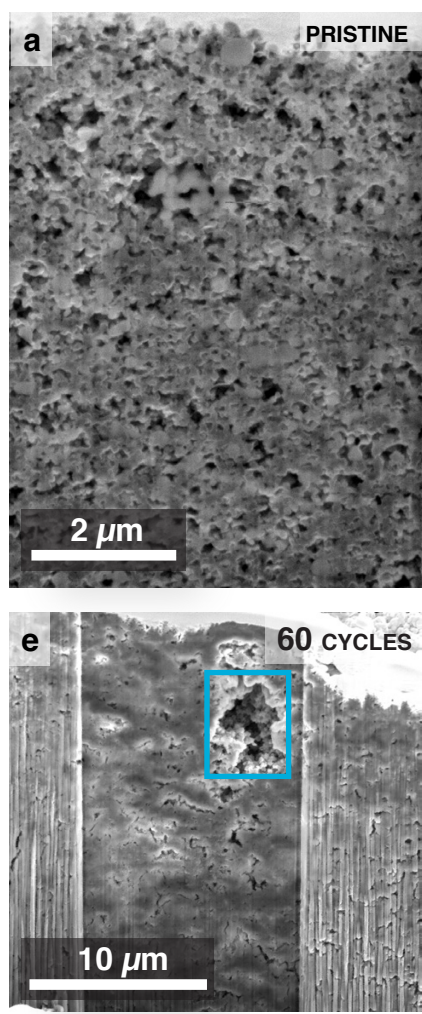
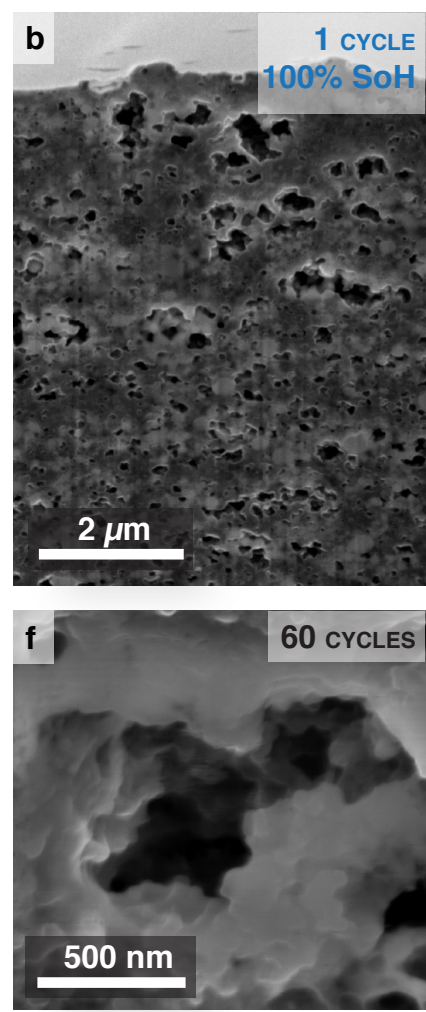
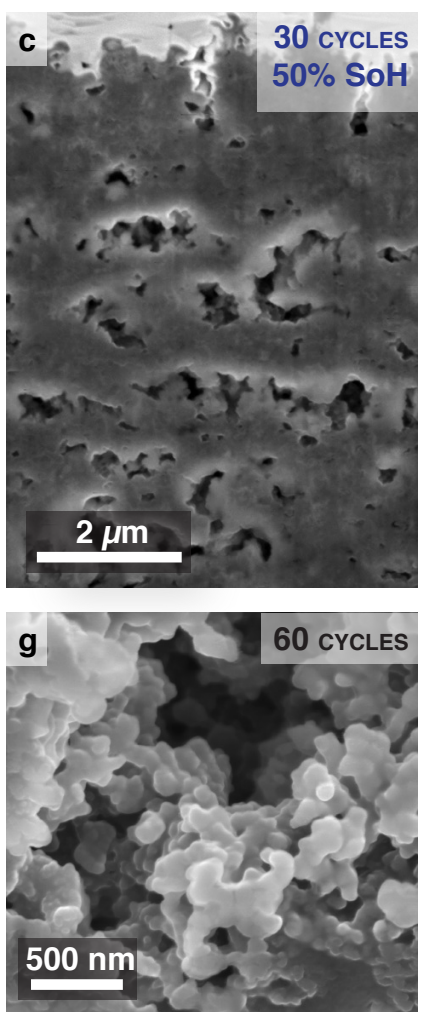
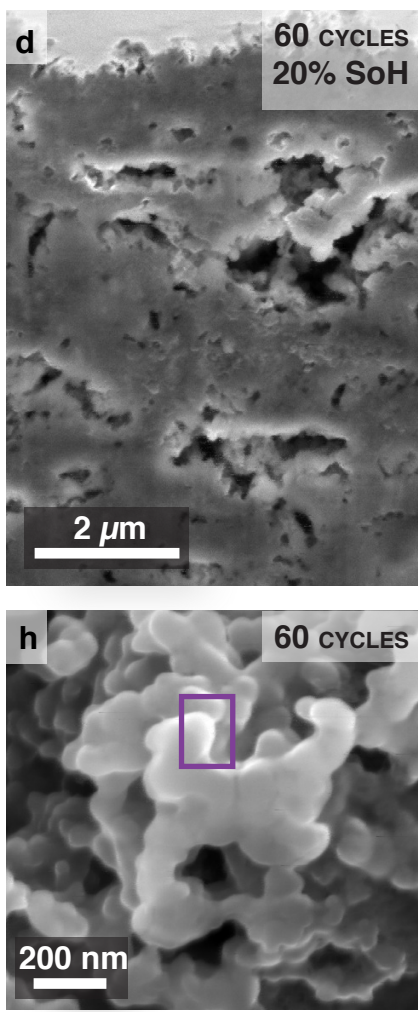

Figure 8: (a-d) SEM micro images of FIB cross sections, showing the pore structure of the electrodes after $0,1,30$, and 60 electrochemical cycles. (e) Analysis region for ( $f, g, h)$. High magnification views of an electrode after cycle $60(20 \%$ SoH $)$ shows evidence of SEI growth on the $\mathrm{C}$ and $\mathrm{Si}$ particle surfaces of the electrode.

views in panels $(\mathrm{f}-\mathrm{h})$ of the complex pore structure formed by $\mathrm{Si}$ and $\mathrm{C}$ particles, with distance from the FIB cut and away from any possible damage from the FIB process. Examining the high resolution images closely, lighter contrast regions are observed on some of the particle agglomerates, which have approximately $100 \mathrm{~nm}$ thickness (see panel $\mathrm{h}$ ). With the growth of the SEI already detected by ssNMR (Figures $4,5,6$ ), these lighter contrast regions likely indicate SEI on particle surfaces.

\section{Discussion}

An irreversible capacity of $760 \mathrm{mAhg}^{-1}$ was measured by electrochemistry in the first cycle, which corresponds to approximately $10 \%$ of the overall endpoint slippage accumulated following 60 cycles (Figure 2-a, b). This loss was correlated with the formation of inorganic SEI decomposition products including $\mathrm{LiF}$ (from ${ }^{19} \mathrm{~F}$ and ${ }^{7} \mathrm{Li}$ ssNMR) (Figure 4); only negligible quantities of organic species, associated with residual DMC and EC and their decomposition products, were detected using ${ }^{13} \mathrm{C}$ ssNMR. $\mathrm{Li}_{2} \mathrm{CO}_{3}$ was not detected by ${ }^{13} \mathrm{C}$ ssNMR in either of the ${ }^{13} \mathrm{C}$-labelled samples, indicating that if present, it was below the detection limit of the experiment. The results are in stark contrast to the binderfree electrode system, where more significant organic SEI formation after the first cycle was seen, ${ }^{23}$ indicating that the CMC binder in the composite system inhibits organic SEI formation and capacity loss. On the basis of the electrochemistry of the conductive C (Figure 3), some of the irreversible capacity loss of the first cycle of the Si composite electrode is ascribed to SEI growth on the surfaces of the conductive $\mathrm{C}$ particles, where a current rate dependent lithiation capacity loss of approximately $200-300 \mathrm{mAhg}^{-1}$ was observed. The result implies that different electrode formulations, with varying ratios of conductive $\mathrm{C}$ to active material, may result in some variation in irreversible capacity loss and SEI formation.

In interval 1, we observed a rapidly declining slippage rate from cycle index 1-3 followed by a steady rate of slippage from cycle index 4-30 (Figure 2-c). The two characteristic electrochemical signatures for $\mathrm{a}-\mathrm{Li}_{\mathrm{x}} \mathrm{Si}$ and $\mathrm{a}-\mathrm{Li}_{\left(\mathrm{x}+\mathrm{x}^{\prime}\right)} \mathrm{Si}$ phase formations (with $\mathrm{x}$ and $\mathrm{x}$ ' having values of approximately 2.0 and 1.5$),{ }^{38}$ initially occurring at 250 and $100 \mathrm{mV}$, were clearly seen in the differential capacity curves (Figure 2-d). The first process is associated with the break-up of the aSi network, to form larger clusters, while the second involves the formation of small clusters such as $\mathrm{Si}-\mathrm{Si}$ dimers and eventual isolated $\mathrm{Si}$ anions. ${ }^{39}$ With $\mathrm{Li}$ being accommodated in the structure of $\mathrm{Si}$, repeated $\mathrm{Si}$ particle expansion and contraction occur during each cycle, illustrated schematically in Figure 9-a. ${ }^{17}$ The expansion likely results in cracking in the SEI formed on the Si particle surfaces resulting in (i) additional $\mathrm{Li}^{+}$ion diffusion pathways to access the Si particles, in addition to the diffusion pathways through the SEI, and (ii) fresh surfaces for SEI formation (see Figure 9-a, left). The SEI growth in this interval was monitored by ssNMR and FIB/SEM (Figures 4 and 8). Using ${ }^{7} \mathrm{Li}$ ssNMR we confirmed an increasing quantity of Li salts (see Figure 
9-a, right). These Li-environments included $\mathrm{LiF}$ (detected by ${ }^{7} \mathrm{Li} /{ }^{19} \mathrm{~F}$ ssNMR), $\mathrm{Li}_{2} \mathrm{CO}_{3}, \mathrm{HCO}_{2} \mathrm{Li}, \mathrm{RCO}_{2} \mathrm{Li}$, and $\mathrm{ROCO}_{2} \mathrm{Li}$ (detected by ${ }^{7} \mathrm{Li} /{ }^{13} \mathrm{C}$ ssNMR). The ${ }^{13} \mathrm{C}$ results clearly demonstrated that the SEI growth was largely due to the decomposition of the organic electrolytes (EC and DMC). Only a minor increase in the amount of LiF in the SEI was observed, showing negligible decomposition of $\mathrm{LiPF}_{6}$ and resulting reactions forming $\mathrm{LiF}$. The result is in agreement with a previous ssNMR study of a Si composite electrode Li-ion system that also detected negligible increases in the quantity of LiF over multiple cycles. ${ }^{47}$ The FIB/SEM analysis (Figure 8) showed surface layers on the $\mathrm{C}$ and $\mathrm{Si}$ particles which were attributed to SEI formation based on the chemical information from the ssNMR. An increased electrode density was attributed to particle agglomeration and SEI build-up within the bulk of the electrode.

The chemical composition of the SEI organics was investigated in detail for the 30 cycle samples, the composition dictating SEI elasticity (and therefore growth) and $\mathrm{Li}^{+}$ion transport from the electrolyte to the $\mathrm{Si}$ particles. By ${ }^{13} \mathrm{C}$ ssNMR correlation and $\mathrm{CP}$ experiments (Figures 5 and 6), we confirmed our assignment of specific resonances to organic oligomer fragments and aliphatic groups in disordered/amorphous environments in the SEI. These environments gave rise to broad resonances from functional groups such as $\mathrm{RCH}_{2} \mathrm{R}, \mathrm{CH}_{3} \mathrm{R}$, and $\mathrm{CH}_{3} \mathrm{CH}_{2} \mathrm{R}$ products that arise from radical (including proton abstraction) reactions of the initial EC and DMC decomposition products. Our previous study of the first lithiation reaction, ${ }^{23}$ suggested that these reactions occur at lower voltages $(<250 \mathrm{mV})$. Correlation ssNMR experiments in this study (Figure 5-b) confirmed chemical bonding between these aliphatic functional groups and $\mathrm{CH}_{2} \mathrm{O}$ groups in the ${ }^{13} \mathrm{C}$-labelled EC sample, providing strong evidence for the presence of SEI molecules such as LBDC, LEC, and $\mathrm{RCO}_{2} \mathrm{Li}$. In addition, at least two different $-\mathrm{OCH}_{2} \mathrm{CH}_{2} \mathrm{O}$ - fragments contained in oligomers and/or $\mathrm{ROCO}_{2} \mathrm{Li}$ salts were observed (Figure 5-c). Analogous ssNMR experiments on the ${ }^{13} \mathrm{C}$-labelled DMC sample supported the presence of LMC. Similar organic environments were detected in our previous study of a binder-free $\mathrm{C} / \mathrm{Si}$ electrode, ${ }^{23}$ indicating strong similarities between the SEI composition of 1-cycle binder-free electrodes and the multicycled composite electrodes investigated in this study. Of note, the thicker SEI formed here resulted in increased overall ${ }^{13} \mathrm{C}$ ssNMR signal intensity, improving the sensitivity of the NMR experiment, allowing, for example, the length and composition of the alkyl chains of the SEI organics (Figures 5 and 6 ) to be analyzed by investigating correlations in the $0-70 \mathrm{ppm}$ region of the ${ }^{13} \mathrm{C}$ ssNMR spectra. These ${ }^{13} \mathrm{C}$ correlation experiments are not practicable on samples with insufficient SEI or with samples prepared with natural abundance ${ }^{13} \mathrm{C}$ electrolytes. Note that even under the current conditions, the experiments still required 321 hours of continuous acquisition on a high field NMR instrument, emphasizing the challenges in characterizing these nano-scale thick interfaces. Interestingly, $\mathrm{LiOH}$ was detected in the multi-cycled composite electrode system here (see Supporting Information) compared to our previous study of a binder-free electrode system where no $\mathrm{LiOH}$ was detected. ${ }^{23}$ The most likely explanation for this is that the CMC binder is difficult to dry completely, introducing trace water into the pristine electrode system. The experimental results here confirm the types of organics contained in the SEI, the decomposition mechanisms of EC and DMC being proposed and debated in the literature. ${ }^{3,6,21,40,48-53}$ Furthermore, the results provide a baseline for which to explore ways to enhance SEI properties and stabilize its growth in the early stages of cycling. Future work will incorporate electrolyte additives to investigate experimentally why additives improve capacity retention in these systems.

On interval 2 (from cycle 30 to 60 ), we observed a declining rate of slippage (see Figure 2-c), compared with a steady slippage rate on interval 1 . To a first approximation, the SEI thickness had stabilized, a quantitative analysis of the ${ }^{13} \mathrm{C}$ ssNMR signal intensities showing evidence for only a minor increase of approximately $10-$ 20\%. The FIB/SEM (Figures 4 and 8) results indicated only minor differences between the morphologies of the cycle 30 and cycle 60 electrodes, the results suggesting some evidence for the presence of fewer smaller pores in the cycle 60 sample compared with the cycle 30 sample. The smaller lithiation capacity of the electrodes in interval 2 results in significantly reduced expansion and contraction of the electrodes during cycling, leading to less crack formation in the SEI, the creation of fewer new $\mathrm{Li}^{+}$ion diffusion pathways through the SEI, and fresh $\mathrm{Li}_{\mathrm{x}} \mathrm{Si}$ surfaces. We therefore ascribe the negligible SEI growth during interval 2, and declining slippage rate, at least in part to this reduced expansion/contraction. Nonetheless, the electrode lithiation capacity continues to decrease. Since the amount of available Li metal in the half cell is large (approximately $23 \mathrm{mg}$ ) compared to the $\mathrm{Li}$ consumed irreversibly, the consumption of $\mathrm{Li}$ metal is not a clear factor in the cell failure. The availability of sufficient Li metal was experimentally confirmed, see Supporting Information. However, the presence of side reactions on the Li metal counter electrode have not been accounted for in our analysis. Mechanical failure in the electrodes is clearly evident, with cracking through the electrode structure observed by SEM (Figure 7), which may result in electrically inactive areas of the electrode. However, a pronounced growth in the quantity of trapped $\mathrm{Li}$ silicides in interval 2 is not evident in our quantitative ${ }^{7} \mathrm{Li}$ ssNMR results, trapped $\mathrm{Li}$ silicides leading to a larger increase in the signal intensity. Interestingly, of the two characteristic a- $\mathrm{Li}_{\mathrm{x}} \mathrm{Si}$ and and $\mathrm{a}-\mathrm{Li}_{\left(\mathrm{x}+\mathrm{x}^{\prime}\right)} \mathrm{Si}$ processes of amorphous $\mathrm{Si}$, a large drop in capacity is seen for the higher voltage process, initially occurring at $250 \mathrm{mV}$, in interval 2 (Figure 2c). This reduced capacity is seen for both lithiation and delithiation (discharge and charge), indicating that the change in the electrochemistry was symmetric.

The increase in signal intensities measured by ssNMR 
Diffusion pathway through SEI

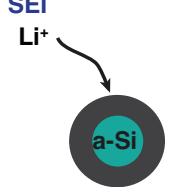

Lithiation leads to SEI cracking
New diffusion pathways

through cracks

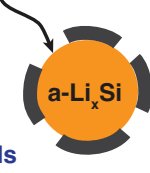

Diffusion pathways through SEI<smiles>[TeH2]</smiles>

Fresh surfaces lead to more SEI growth

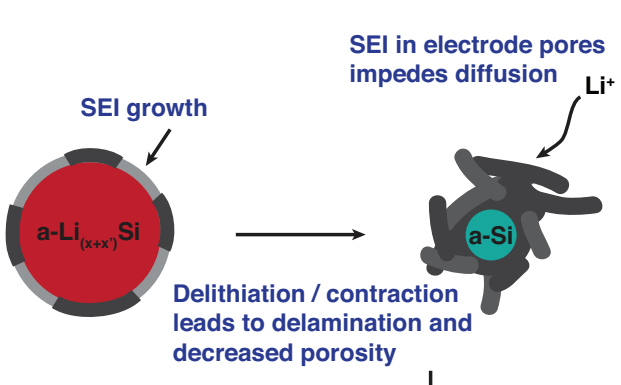

amorphous $\mathrm{Si} \sim$ a-Si

a-Si

a-Li $\mathbf{X i}_{\mathbf{S}}$

$a-i_{\left(x+x^{\prime}\right)} S i$

Increasing $\mathrm{Li}$

$x \sim 2.0 \quad x \sim 1.5$

Repeated electrochemical cycling

(b) $\mathrm{Li}^{+}$ion diffusion in the increasingly dense electrode structure

Cycle 2-30: Uniform lithiation

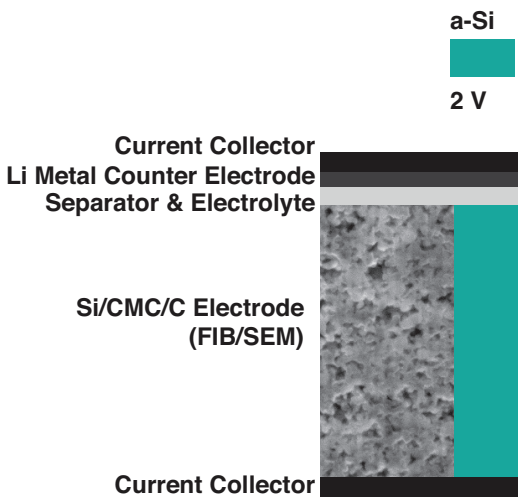

Current Collector

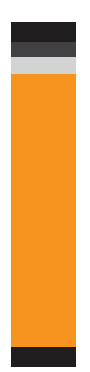

Cycles 30-60: Surface particle lithiation

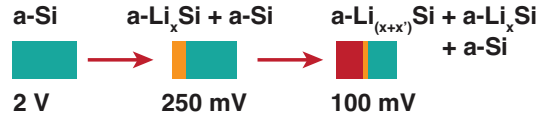

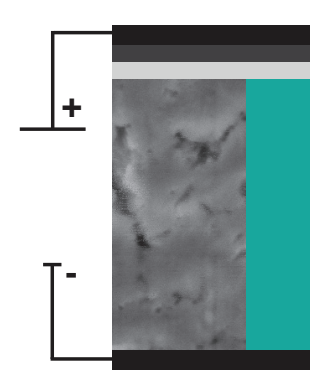
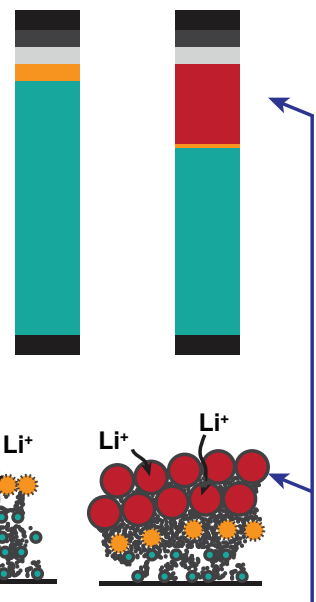

$\mathrm{Li}^{+}$ion diffusion restricted to surface regions near separator and of large pores due to SEI delamination and dense electrode structure

(c) Capacity loss and evolving kinetics

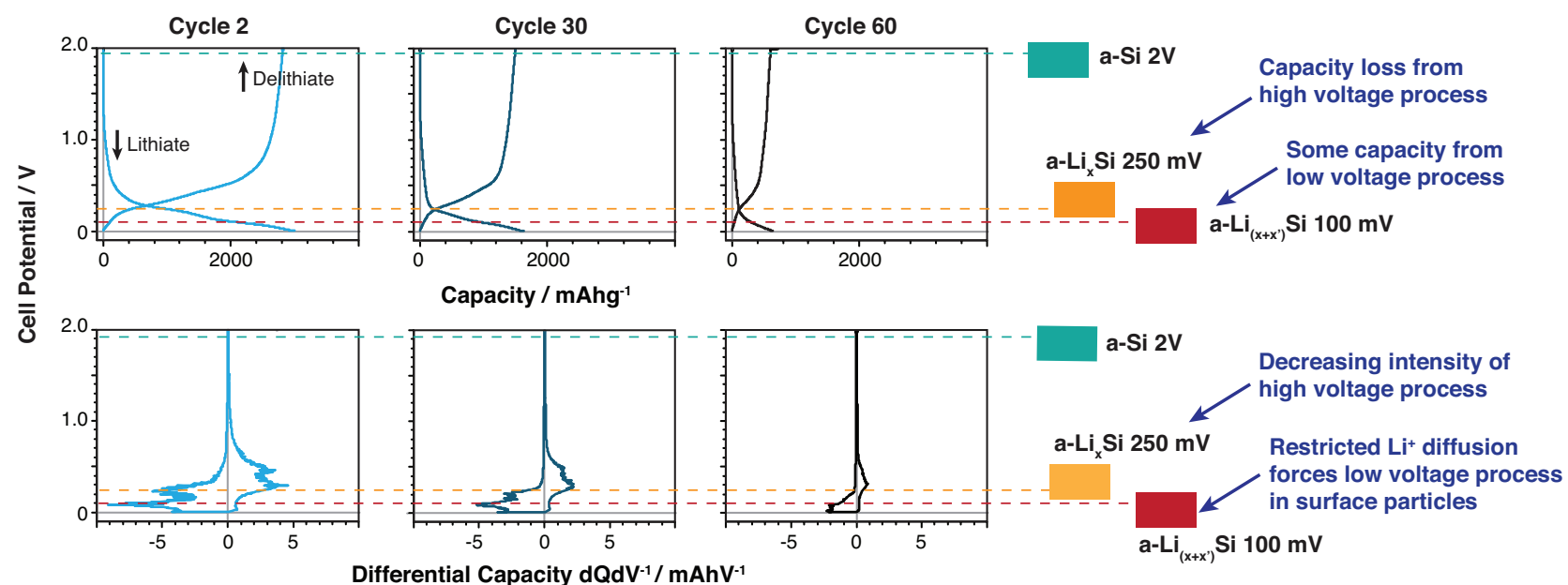

Figure 9: Multi-length scale model of SEI growth and $\mathrm{Li}^{+}$ion diffusion as failure mechanisms for a Si composite electrode, electrochemically cycled in a half-cell configuration against a Li metal counter electrode. (a) Schematic showing nanoscale processes: $\mathrm{Li}^{+}$ion diffusion through cracks in the SEI, additional SEI growth, and delamination from Si particle surfaces. (b) Schematic showing microscale processes: electrode pore structure becomes more dense, restricting $\mathrm{Li}^{+}$diffusion to surface regions near the separator and to surface regions of large pores formed due to particle agglomeration and mechanical stresses. The FIB/SEM (from Figure 8) electrode cross sections show the increasing density of the electrode pore structure. Note that the carbon and binder are omitted from the cartoon below the FIB/SEM cross-sections for clarity, the true electrode structure being more dense than implied. (c) Atomic scale processes: Si electrochemistry (from Figure 2-c) at cycle 2, 30, and 60 , highlighting the evolution of the higher $(250 \mathrm{mV})$ and lower $(100 \mathrm{mV})$ voltage amorphous Si lithiation processes and corresponding capacity loss. 
is noticeably smaller than predicted on the basis of the endpoint slippages $\Delta_{1} / \Delta_{2}$ (see Figure 2-a, b), assuming all the slippage is due to inorganic or organic SEI formation. Furthermore, no new chemical environments are detected between 30 and 60 cycles, in any of the ssNMR spectra. This suggests that additional factors beyond SEI growth contribute to the endpoint slippage. For example, soluble SEI products contained in the electrolyte $^{46}$ have not been accounted for in this ssNMR study.

In contrast with the voltage limited cycling used in this study, two key studies that have investigated the role that SEI formation plays in capacity loss have used capacity limited cycling. ${ }^{13,14}$ In capacity limited cycling, the low voltage limit steadily decreases on cycling, as $\mathrm{Li}$ is consumed in the formation of the SEI (and in other irreversible processes), while the discharge capacity in each cycle is held constant. Generally, following the seminal paper by Obvrovac, ${ }^{15}$ the capacity limited cycling is thought to occur via the reaction of Li with the outer shell of the crystalline Si particles, resulting in an outer amorphous $\mathrm{Si}$ shell and a crystalline core. Eventually, as the voltage limit decreases on cycling, all of the crystalline Si core is lithiated. At this point, rapid cell failure occurs. For example, Radvanyi et al. ${ }^{13}$ showed a rapid failure process after approximately 50 electrochemical cycles with a capacity of $1200 \mathrm{mAhg}^{-1}$; this occurred when the cell lower voltage limit had dropped from its initial value of $200 \mathrm{mV}$ in the 1st cycle to $30 \mathrm{mV}$. Similarly, Oumellal et al., ${ }^{14}$ also observed a rapid failure process at the cycle index of approximately 90 cycles when their voltage limit dropped from $100 \mathrm{mV}$ to $5 \mathrm{mV}$ (initially cycling near $100 \mathrm{mV}$ due to their capacity limit of $1200 \mathrm{mAhg}^{-1}$ ). The exact failure mechanisms seen under this cycling regime may differ somewhat than the mechanisms relevant to our study because the mechanical stresses, and the time spent at low potentials differ: (i) the stresses associated with the lithiation of the crystalline core in the capacity limited cycling are very different than the lithiation of the more homogeneous amorphous silicon particles in the voltage limited cycling in this study, (ii) we have shown that different degradation processes and different SEI products form on cycling down to the low voltage limit. ${ }^{23}$ Despite these differences, reduced $\mathrm{Li}^{+}$ ion diffusion through the electrode and through the SEI appears to be a failure mode when using both methods. Oumellal et al. ${ }^{14}$ present a model where SEI build-up in the pores of the electrode increase the tortuosity of the electrode. Radvanyi et al. present a model for failure that shows a $\mathrm{Li}^{+}$ion concentration gradient across the electrode, where the electrode is preferentially lithiated at the top of the electrode, next to the separator (i.e., the reaction is limited by the flux of $\mathrm{Li}^{+}$ions), due to the lithium transport being impeded through the bulk of the electrode. ${ }^{13}$

An extension to these Si electrode failure models is presented in Figure 9. SEI growth on particle surfaces due to the large volume expansion associated with Si- particle lithiation is captured schematically in Figure 9-a. ${ }^{17}$ Delamination of the SEI into the pores of the electrode, coupled with the mechanical stresses and particle agglomeration, result in the increased electrode density confirmed by FIB/SEM. In the early stages of cycling, $\mathrm{Li}^{+}$ions can access the entire porous electrode structure, described in Figure 9-b, left. Consequently, the capacity associated with both the characteristic a- $\mathrm{Li}_{\mathrm{x}} \mathrm{Si}$ and $\mathrm{a}-\mathrm{Li}_{(\mathrm{x}+\mathrm{x})}$ Si processes is achieved, and continuous volume expansion and contraction result in pronounced SEI growth, which we confirmed by ssNMR (Figure 4). The dense electrode structure and increased tortuosity seen at later stages of cycling likely impedes $\mathrm{Li}^{+}$ion diffusion through the bulk of the electrode, described schematically in Figure 9-b, right. In this end failure mode, the decreasing capacity associated with the higher voltage $\mathrm{Li}_{\mathrm{x}} \mathrm{Si}(250 \mathrm{mV}$ ) process, Figure 9-c, coupled with the SEI stabilization confirmed by ssNMR and FIB/SEM, strongly support a model where $\mathrm{Li}^{+}$ ion diffusion is limited to surface regions of the electrode. These accessible surface regions are likely located near the electrolyte saturated separator and/or to surface regions of the large voids that may still be accessible deeper inside the electrode, nearer to the current collector. In this surface-limited diffusion model, the reaction will still occur sequentially, first via the higher voltage $(250 \mathrm{mV})$ process, breaking apart the $\mathrm{a}-\mathrm{Si}$ network to form $\mathrm{a}-\mathrm{Li}_{\mathrm{x}} \mathrm{Si}$. It is then kinetically more facile for the lithium ions to continue to react with the $\mathrm{a}-\mathrm{Li}_{\mathrm{x}} \mathrm{Si}$ network to form $\mathrm{a}-\mathrm{Li}\left(\mathrm{x}+\mathrm{x}^{\prime}\right) \mathrm{Si}$, than for the $\mathrm{Li}^{+}$ions to diffuse further into the electrode. This will result in a front of $\mathrm{a}-\mathrm{Li}_{\left(\mathrm{x}+\mathrm{x}^{\prime}\right)} \mathrm{Si}$ that moves through the electrode, from the separator to the current collector, and from the surface of the agglomerated particles into the center. Furthermore, it will be associated with the electrochemical signature of the $2^{\text {nd }}$ process. This has analogies with the $1^{\text {st }}$ lithiation of crystalline $\mathrm{Si}$, where the reaction proceeds at approximately $100 \mathrm{mV}$ to form a mixture of small Si dimers and isolated Si. ${ }^{10}$ The large volume expansion associated with this $\mathrm{a}-\mathrm{Li}_{\left(\mathrm{x}+\mathrm{x}^{\prime}\right)} \mathrm{Si}$ phase formation is expected to further impede $\mathrm{Li}^{+}$ion diffusion through the bulk of the electrode (see Figure 9-b, right, bottom). Inaccessible Si results in further lithiation capacity loss and decreased volume expansion of the electrode. The decreased volume expansion would then reduce the SEI cracking and number of fresh surfaces for which to form more SEI, in agreement with the decreased SEI growth detected on interval 2 by ssNMR. By cycle 60 , the higher voltage $\left(\mathrm{a}-\mathrm{Li}_{\mathrm{x}} \mathrm{Si}, 250 \mathrm{mV}\right) \mathrm{Si}$ process is absent, indicating that the thickness of the surface layer and amount of accessible $\mathrm{Si}$ continues to decrease in the end-failure mode. The relationship between $\mathrm{Li}^{+}$ion diffusion concentration gradients, electrode porosity, and tortuosity, are well-known; for example, we have previously investigated inhomogeneous electrochemical reactions through porous $\mathrm{LiFePO}_{4}$ electrodes using in situ energy-dispersive X-ray diffraction. ${ }^{54}$ In the study, sim- 
ulations showed that reducing electrode porosity from $35 \%$ to $15 \%$, resulted in $\mathrm{Li}^{+}$ion concentration gradients (Li fraction $/ \mathrm{mm}$ ) that increased by a factor of approximately $2-3$, depending on active material particle size distributions. These concentration gradients then resulted in inhomogeneous particle reactions across the electrode. With the porosity of the Si electrodes in this study dramatically decreasing during repeated cycling, $\mathrm{Li}^{+}$ion concentration gradients are reasonably expected to have a significant impact on the kinetics of the system.

\section{Conclusions}

$\mathrm{Si}$ electrode failure was investigated by cycling $\mathrm{Si} / \mathrm{CMC} / \mathrm{C}$ composite Si electrodes at their full capacity, between the voltage potential limits of $1 \mathrm{mV}$ and 2 $\mathrm{V}$, at a constant current rate. The SEI growth, formed from the reduction of a standard $1 \mathrm{M} \mathrm{LiPF}_{6}$ in $\mathrm{EC} / \mathrm{DMC}$ electrolyte, was directly measured and quantified using ${ }^{7} \mathrm{Li},{ }^{19} \mathrm{~F}$, and ${ }^{13} \mathrm{C}$ ssNMR. The accumulation of the SEI in the pores of the electrode was demonstrated by FIB/SEM. In the first cycle, the SEI composition was dominated by inorganic decomposition products, including $\mathrm{LiF}$ and additional Li salts. After the lithiation capacity had dropped to only $50 \%$ of its initial value, the bulk of the SEI growth had already occurred and significant quantities of organic SEI decomposition products were detected. Using ${ }^{13} \mathrm{C}$ ssNMR correlation experiments, we showed definitive evidence for at least two different $-\mathrm{OCH}_{2} \mathrm{CH}_{2} \mathrm{O}-$ fragments, present in $\mathrm{ROCO}_{2} \mathrm{Li}$ and oligomeric species. Chemical bonds between $\mathrm{CH}_{2} \mathrm{O}$ and functional groups $\mathrm{CH}_{3} \mathrm{R}, \mathrm{RCH}_{2} \mathrm{R}$, and $\mathrm{CH}_{3} \mathrm{CH}_{2} \mathrm{R}$ were confirmed, showing strong evidence for the presence of $\mathrm{LEC}, \mathrm{LBDC}$, and $\mathrm{RCO}_{2} \mathrm{Li}$ SEI decomposition products. The presence of $\mathrm{HCO}_{2} \mathrm{Li}$, $\mathrm{Li}_{2} \mathrm{CO}_{3}$, and $\mathrm{LMC}$, were also confirmed. Interestingly, subsequent cycling and degradation, down to a $20 \%$ lithiation capacity of the electrode, was not correlated with significant SEI growth or a significant evolution in the chemical composition. Furthermore, no clear electrode structure changes were evident by FIB/SEM. The decreasing rate of lithiation endpoint slippage correlates with less $\mathrm{Si}$ being lithiated and delithiated at later stages of cycling. Also evident by the electrochemical curves, the kinetics for a-Si particle lithiation had evolved.

Our results support a model for lithiation capacity loss that can be roughly approximated into two stages. In the first stage, the capacity loss is correlated with a growth in the SEI and increasing electrode tortuosity. The increased electrode density observed by FIB/SEM was ascribed to a combination of SEI formation on the Si particles, particle agglomeration, and SEI exfoliation from particle surfaces filling the pores of the electrode. In the second stage, the decreasing lithiation capacity is attributed to kinetics. The results support a model where $\mathrm{Li}^{+}$ion diffusion is severely limited by the increased electrode tortuosity through the bulk of the electrode. Surface-limited diffusion is reflected in the electrochemistry, which shows a steadily decreasing measured capacity from the process typically associated with $\mathrm{Li}_{\mathrm{x}} \mathrm{Si}(\mathrm{x} \sim 2.0)$ formation.

Acknowledgement This work was partially supported by the Assistant Secretary for Energy Efficiency and Renewable Energy, Office of Vehicle Technologies of the U.S. Department of Energy under Contract No. DE-AC02-05CH11231, under the Batteries for Advanced Transportation Technologies (BATT) Program subcontract \#7057154 and the European Commission (EC), through the project EuroLion. G.D. and C.D. acknowledge funding from the ERC under grants 259619 PHOTO EM and 312483 ESTEEM2. A.L.M. is an awardee of a Schiff Foundation Studentship and a nanoDTC Associate. M.L is an awardee of the Weizmann Institute of Science - National Postdoctoral Award for Advancing Women in Science and thanks the EU Marie Curie intra-European fellowship for funding. We also thank members of the EuroLion Collaboration, Prof. Steven P. Brown (Warwick), and Dr. John M. Griffin (Lancaster) for helpful discussions.

Supporting Information Available: Further FIB/SEM/TEM electrode characterization and ssNMR experimental details and spectra are provided. This material is available free of charge via the Internet at http://pubs . acs .org/.

\section{References}

(1) Peled, E. J. Electrochem. Soc. 1979, 126, 2047-2051.

(2) Fong, R.; Von Sacken, U.; Dahn, J. R. J. Electrochem. Soc 1990, 137, 2009-2013.

(3) Peled, E.; Golodnitsky, D.; Ardel, G. J. Electrochem. Soc. 1997, 144, L208-L210.

(4) Xu, K. Chem. Rev. 2004, 104, 4303-4418.

(5) Winter, M. Z. Phys. Chem. 2009, 223, 1395-1406.

(6) Xu, K.; von Cresce, A. J. Mater. Chem. 2011, 21, 98499864

(7) Xu, K. Chem. Rev. 2014, 114, 11503-11618.

(8) Obrovac, M. N.; Christensen, L. Electrochem. Solid-State Lett. 2004, 7, A93-A96.

(9) Obrovac, M. N.; Chevrier, V. L. Chem. Rev. 2014, 114, 11444-11502

(10) Key, B.; Bhattacharyya, R.; Morcrette, M.; Seznéc, V.; Tarascon, J.-M.; Grey, C. P. J. Am. Chem. Soc. 2009, 131, 9239-9249.

(11) Beaulieu, L. Y.; Eberman, K. W.; Turner, R. L.; Krause, L. J.; Dahn, J. R. Electrochem. Solid-State Lett. 2001, 4, A137-A140.

(12) Besenhard, J. O.; Yang, J.; Winter, M. J. Power Sources $\mathbf{1 9 9 7}, 68,87-90$

(13) Radvanyi, E.; Porcher, W.; De Vito, E.; Montani, A.; Franger, S.; Jouanneau Si Larbi, S. Phys. Chem. Chem. Phys. 2014, 16, 17142-17153.

(14) Oumellal, Y.; Delpuech, N.; Mazouzi, D.; Dupré, N.; Gaubicher, J.; Moreau, P.; Soudan, P.; Lestriez, B.; Guyomard, D. J. Mater. Chem. 2011, 21, 6201-6208.

(15) Obrovac, M. N.; Krause, L. J. J. Electrochem. Soc. 2007, 154, A103-A108.

(16) Chan, C. K.; Peng, H.; Liu, G.; McIlwrath, K.; Zhang, X. F.; Huggins, R. A.; Cui, Y. Nat. Nanotechnol. 2008, 3, 31-35. 
(17) Wu, H.; Chan, G.; Choi, J. W.; Ryu, I.; Yao, Y.; McDowell, M. T.; Lee, S. W.; Jackson, A.; Yang, Y.; Hu, L.; Cui, Y. Nat. Nanotechnol. 2012, 7, 310-315.

(18) Aurbach, D.; Gamolsky, K.; Markovsky, B.; Gofer, Y.; Schmidt, M.; Heider, U. Electrochim. Acta 2002, 47, 14231439 .

(19) El Ouatani, L.; Dedryvère, R.; Siret, C.; Biensan, P.; Reynaud, S.; Iratçabal, P.; Gonbeau, D. J. Electrochem. Soc. 2009, 156, A103-A113.

(20) Zhang, S. S. J. Power Sources 2006, 162, 1379-1394.

(21) Schroder, K. W.; Celio, H.; Webb, L. J.; Stevenson, K. J. J. Phys. Chem. C 2012, 116, 19737-19747.

(22) Malmgren, S.; Ciosek, K.; Lindblad, R.; Plogmaker, S.; Kühn, J.; Rensmo, H.; Edström, K.; Hahlin, M. Electrochim. Acta 2013, 105, 83-91.

(23) Michan, A. L.; Leskes, M.; Grey, C. P. Chem. Mater. 2016, 28, 385-398.

(24) Morcombe, C. R.; Zilm, K. W. J. Magn. Reson. 2003, 162, 479-486.

(25) Apperley, D. C.; Harris, R. K.; Hodgkinson, P. Solid State NMR. Momentum Press, New York, 2012.

(26) Massiot, D.; Fayon, F.; Capron, M.; King, I.; Le Calvé, S.; Alonso, B.; Durand, J.-O.; Bujoli, B.; Gan, Z.; Hoatson, G. Magn. Reson. Chem. 2002, 40, 70-76.

(27) Thakur, R. S.; Kurur, N. D.; Madhu, P. K. Chem. Phys. Lett. 2006, 426, 459-463.

(28) Lesage, A.; Bardet, M.; Emsley, L. J. Am. Chem. Soc. 1999, 121, 10987-10993.

(29) Bax, A.; Freeman, R.; Kempsell, S. P. J. Am. Chem. Soc. 1980, 102, 4849-4851.

(30) Bax, A.; Freeman, R.; Frenkiel, T. A. J. Am. Chem. Soc. 1981, 103, 2102-2104.

(31) Cadars, S.; Sein, J.; Duma, L.; Lesage, A.; Pham, T. N.; Baltisberger, J. H.; Brown, S. P.; Emsley, L. J. Magn. Reson. 2007, 188, 24-34.

(32) Opella, S. J.; Frey, M. H. J. Am. Chem. Soc. 1979, 101, $5854-5856$.

(33) Smith, A. J.; Burns, J. C.; Xiong, D.; Dahn, J. R. J. Electrochem. Soc. 2011, 158, A1136-A1142.

(34) Iaboni, D. S. M.; Obrovac, M. N. J. Electrochem. Soc. 2015, 163, A255-A261.

(35) Du, Z.; Hatchard, T. D.; Dunlap, R. A.; Obrovac, M. N. J. Electrochem. Soc. 2015, 162, A1858-A1863.

(36) Smith, A. J.; Burns, J. C.; Trussler, S.; Dahn, J. R. J. Electrochem. Soc. 2010, 157, A196-A202.

(37) Li, J.; Dahn, J. R. J. Electrochem. Soc. 2007, 154, A156A161.

(38) Ogata, K.; Salager, E.; Kerr, C. J.; Fraser, A. E.; Ducati, C.; Morris, A. J.; Hofmann, S.; Grey, C. P. Nat. Commun. 2014, 5, 1-11.

(39) Key, B.; Morcrette, M.; Tarascon, J.-M.; Grey, C. P. J. Am. Chem. Soc. 2011, 133, 503-512.
(40) Aurbach, D. J. Power Sources 2000, 89, 206-218.

(41) MacKenzie, K. J. D.; Smith, M. E. In Multinuclear SolidState Nuclear Magnetic Resonance of Inorganic Materials, 1st ed.; Cahn, R. W., Ed.; Pergamon materials series; Pergamon: Oxford, 2002.

(42) Philippe, B.; Dedryvère, R.; Gorgoi, M.; Rensmo, H.; Gonbeau, D.; Edström, K. Chem. Mater. 2013, 25, 394404.

(43) Meyer, B. M.; Leifer, N.; Sakamoto, S.; Greenbaum, S. G.; Grey, C. P. Electrochem. Solid-State Lett. 2005, 8, A145A148.

(44) Kim, T.; Park, S.; Oh, S. M. J. Electrochem. Soc. 2007, 154, A1112-A1117.

(45) Philippe, B.; Dedryvère, R.; Allouche, J.; Lindgren, F.; Gorgoi, M.; Rensmo, H.; Gonbeau, D.; Edström, K. Chem. Mater. 2012, 24, 1107-1115.

(46) Huff, L. A.; Tavassol, H.; Esbenshade, J. L.; Xing, W.; Chiang, Y.-M.; Gewirth, A. A. ACS Appl. Mater. Interfaces 2016, 8, 371-380.

(47) Delpuech, N.; Dupré, N.; Mazouzi, D.; Gaubicher, J.; Moreau, P.; Bridel, J. S.; Guyomard, D.; Lestriez, B. Electrochem. Commun. 2013, 33, 72-75.

(48) Soto, F. A.; Ma, Y.; Martínez de la Hoz, J. M.; Seminario, J. M.; Balbuena, P. B. Chem. Mater. 2015, 27, 79908000 .

(49) Aurbach, D.; Zinigrad, E.; Cohen, Y.; Teller, H. Solid State Ionics 2002, 148, 405-416.

(50) Dedryvère, R.; Laruelle, S.; Grugeon, S.; Gireaud, L.; Tarascon, J. M.; Gonbeau, D. J. Electrochem. Soc. 2005, 152, A689-A696.

(51) Nie, M.; Chalasani, D.; Abraham, D. P.; Chen, Y.; Bose, A.; Lucht, B. L. J. Phys. Chem. C 2013, 117, 1257-1267.

(52) Tavassol, H.; Buthker, J. W.; Ferguson, G. A.; Curtiss, L. A.; Gewirth, A. A. J. Electrochem. Soc. 2012, 159 , A730-A738.

(53) Wang, Y.; Nakamura, S.; Ue, M.; Balbuena, P. B. J. Am. Chem. Soc. 2001, 123, 11708-11718.

(54) Strobridge, F. C.; Orvananos, B.; Croft, M.; Yu, H.-C.; Robert, R.; Liu, H.; Zhong, Z.; Connolley, T.; Drakopoulos, M.; Thornton, K.; Grey, C. P. Chem. Mater. 2015, 27, $2374-2386$. 


\section{Graphical TOC Entry}

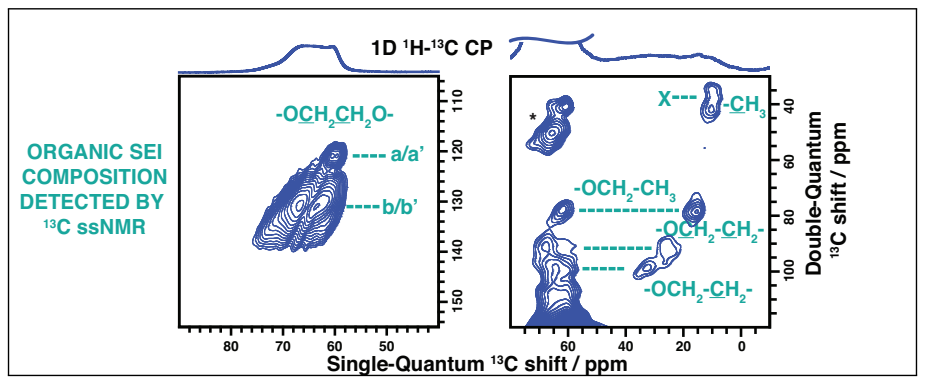

